\title{
Neuropathological diagnosis of vascular cognitive impairment and vascular dementia with implications for Alzheimer's disease
}

\author{
Raj N. Kalaria ${ }^{1}$
}

Received: 11 February 2016 / Revised: 23 March 2016 / Accepted: 24 March 2016 / Published online: 9 April 2016

(C) The Author(s) 2016. This article is published with open access at Springerlink.com

\begin{abstract}
Vascular dementia $(\mathrm{VaD})$ is recognised as a neurocognitive disorder, which is explained by numerous vascular causes in the general absence of other pathologies. The heterogeneity of cerebrovascular disease makes it challenging to elucidate the neuropathological substrates and mechanisms of $\mathrm{VaD}$ as well as vascular cognitive impairment (VCI). Consensus and accurate diagnosis of $\mathrm{VaD}$ relies on wide-ranging clinical, neuropsychometric and neuroimaging measures with subsequent pathological confirmation. Pathological diagnosis of suspected clinical $\mathrm{VaD}$ requires adequate postmortem brain sampling and rigorous assessment methods to identify important substrates. Factors that define the subtypes of $\mathrm{VaD}$ include the nature and extent of vascular pathologies, degree of involvement of extra and intracranial vessels and the anatomical location of tissue changes. Atherosclerotic and cardioembolic diseases appear the most common substrates of vascular brain injury or infarction. Small vessel disease characterised by arteriolosclerosis and lacunar infarcts also causes cortical and subcortical microinfarcts, which appear to be the most robust substrates of cognitive impairment. Diffuse WM changes with loss of myelin and axonal abnormalities are common to almost all subtypes of VaD. Medial temporal lobe and hippocampal atrophy accompanied by variable hippocampal sclerosis are also features of $\mathrm{VaD}$ as they are of Alzheimer's disease. Recent observations suggest that there is a vascular basis for neuronal atrophy in both the temporal and frontal lobes in $\mathrm{VaD}$ that is entirely independent of any Alzheimer pathology. Further knowledge
\end{abstract}

Raj N. Kalaria

r.n.kalaria@ncl.ac.uk

1 Institute of Neuroscience, Newcastle University, Campus for Ageing and Vitality, Newcastle upon Tyne NE4 5PL, UK on specific neuronal and dendro-synaptic changes in key regions resulting in executive dysfunction and other cognitive deficits, which define VCI and $\mathrm{VaD}$, needs to be gathered. Hereditary arteriopathies such as cerebral autosomal dominant arteriopathy with subcortical infarcts and leukoencephalopathy or CADASIL have provided insights into the mechanisms of dementia associated with cerebral small vessel disease. Greater understanding of the neurochemical and molecular investigations is needed to better define microvascular disease and vascular substrates of dementia. The investigation of relevant animal models would be valuable in exploring the pathogenesis as well as prevention of the vascular causes of cognitive impairment.

Keywords Alzheimer's disease · Cerebral amyloid angiopathy $\cdot$ Cerebrovascular degeneration · Dementia . Neuropathology $\cdot$ Small vessel disease $\cdot$ Vascular dementia

\section{Introduction}

Cerebrovascular disease (CVD) is the second most common cause of age-related cognitive impairment and dementia, which is widely recognised as vascular dementia $(\mathrm{VaD})$. $\mathrm{VaD}$ culminates from global or localised effects of vascular disease, which incurs stroke injury and other tissue perfusion changes. $\mathrm{VaD}$ is characterised as a neurocognitive disorder, but also incorporates behavioural symptoms, locomotor abnormalities and autonomic dysfunction. Vascular cognitive impairment (VCI) results from all causes of CVD including cardiovascular that lead to early and late plus severe forms of dementia syndromes. Within CVD, the most common vascular contributor to dementia is likely cerebral small vessel disease (SVD), which describes a range of clinical, neuroimaging and pathological features. 
SVD has taken precedence as a radiological concept, but refers to an intracranial disorder that encompasses pathological changes within and at the surfaces of brain microvessels including perforating arteries and arterioles, capillaries and venules. SVD involves tissue injury in both the cortical and subcortical grey and white matter (WM). SVD, however, may often coexist with atherosclerosis involving large extracranial vessels and embolic disease [103].

In this article, I review the brief history of our current understanding of $\mathrm{VaD}$, various criteria incorporating clinical, neuropsychological and pathological features that have been proposed over the years and key vascular lesions and tissue changes, which contribute to dementia. I convey some opinions about brain sampling and consider some of the rarer causes of VCI and $\mathrm{VaD}$ and how these can be investigated. It is clear that despite the strong and unambiguous evidence that vascular factors and vascular disease contribute to the global burden of brain disease, dementia prognosis and research has mostly focused on Alzheimer's disease (AD). Vascular causes of dementia and their contribution to neurodegenerative processes have not been widely emphasised.

\section{Historical aspects and nosology}

One could begin with Thomas Willis and apoplexy, but the concept that gradual strangulation of the brain causes cognitive and behavioural deficits was distinguished just over 100 years ago [18]. Both Alzheimer and Kraeplin had reasoned that old age-associated progressive hardening of the arteries lead to arteriosclerotic dementia. The label arteriosclerotic dementia attributed to cerebral softening with loss of relatively large volume $(50-100 \mathrm{~mL})$ of brain tissue was used in hospital records as late as the 1960s [165]. The diagnosis of arteriosclerotic dementia often superseded that of $\mathrm{AD}$, which became to be frequently diagnosed in the late 1970s on whether it is a form of pre-senile or senile dementia. Unlike arteriosclerotic dementia, the current formulation of $\mathrm{VaD}$ has transformed as a distinct condition over the past 25 years. $\mathrm{VaD}$ or cerebrovascular dementia implies a clinically diagnosed dementia syndrome comprising subtypes with both ischemic and haemorrhagic aetiologies [142]. As AD became more commonly recognised, VaD was often similarly characterised as a primary memoryassociated dementia but involving vascular causes.

Otto Binswanger could probably be acknowledged to have conveyed the notion of the existence of subclasses of $\mathrm{VaD}$. He described subcortical arteriosclerotic encephalopathy or a type of SVD-related dementia [18]. This was described after pathological verification of cerebral WM disorder in a group of patients with hypertensive disease.
Further descriptions of distinct pathological changes in cerebral vessels were another step forward towards classification of subtypes. In 1937, W Schultz had described drusige entrartung or congophilic amyloid angiopathy in some patients. More recently, C. Miller Fisher recognised for his profound proposal indicated that cerebrovascular dementia is a matter of both large and small strokes and provided clear accounts of lacunar syndromes [56]. Multiple small infarcts in association with hypertension (état lacunaire) are the commonest pathological changes linked to VaD. It is characterised by abrupt episodes, which lead to weakness, slowness, dysarthria, dysphagia, small-stepped gait, brisk reflexes and extensor plantar responses. All these signs are largely present by the time mental deterioration occurs [73]. The recognition of subtypes of clinical VaD was clearly an important step towards current pathological classifications based on vascular aetiology. It was subsequently recognised that multi-infarct dementia predominantly results from cortical infarcts attributed to large vessel disease, whereas dementia associated with subcortical ischemic lesions or Binswanger's disease involving subcortical structures and the WM results from changes in intracranial small vessels (Table 1).

\section{The continuum of VCI and vascular cognitive disorder}

VCI came into existence to empower a single label for all conditions in any cognitive domain that has a vascular origin or impaired brain perfusion [118]. While useful, it is challenging to consistently correlate the degree of pathological changes with the degree of impaired cognition in the continuum of VCI $[65,72,118]$. The description vascular cognitive disorder [145] also incorporates a continuum comprising cognitive disorders of vascular aetiology with diverse pathologies and clinical manifestations. Therefore, in the most recent diagnostic and statistical manual of mental disorders (DSM) or DSM-V criteria and guidelines, the categories of mild and major vascular cognitive disorders were introduced [8]. Vascular cognitive disorder indicated a global diagnostic category, restricting the term VCI to patients whose cognitive impairment fell short of dementia [142]. The major neurocognitive disorder classification, meant to describe frank dementia as a substitute for $\mathrm{VaD}$, appears to fit better with patients and more adapted to neurodegenerative cognitive disorders for which memory impairment is not predominant, but comprises substantial frontal lobe pathology [146].

Cognitive impairment or dementia following stroke is recognised to be relatively common [102, 129]. Incident dementia after stroke or post-stroke dementia (PSD) has become better defined in recent years. PSD may develop 


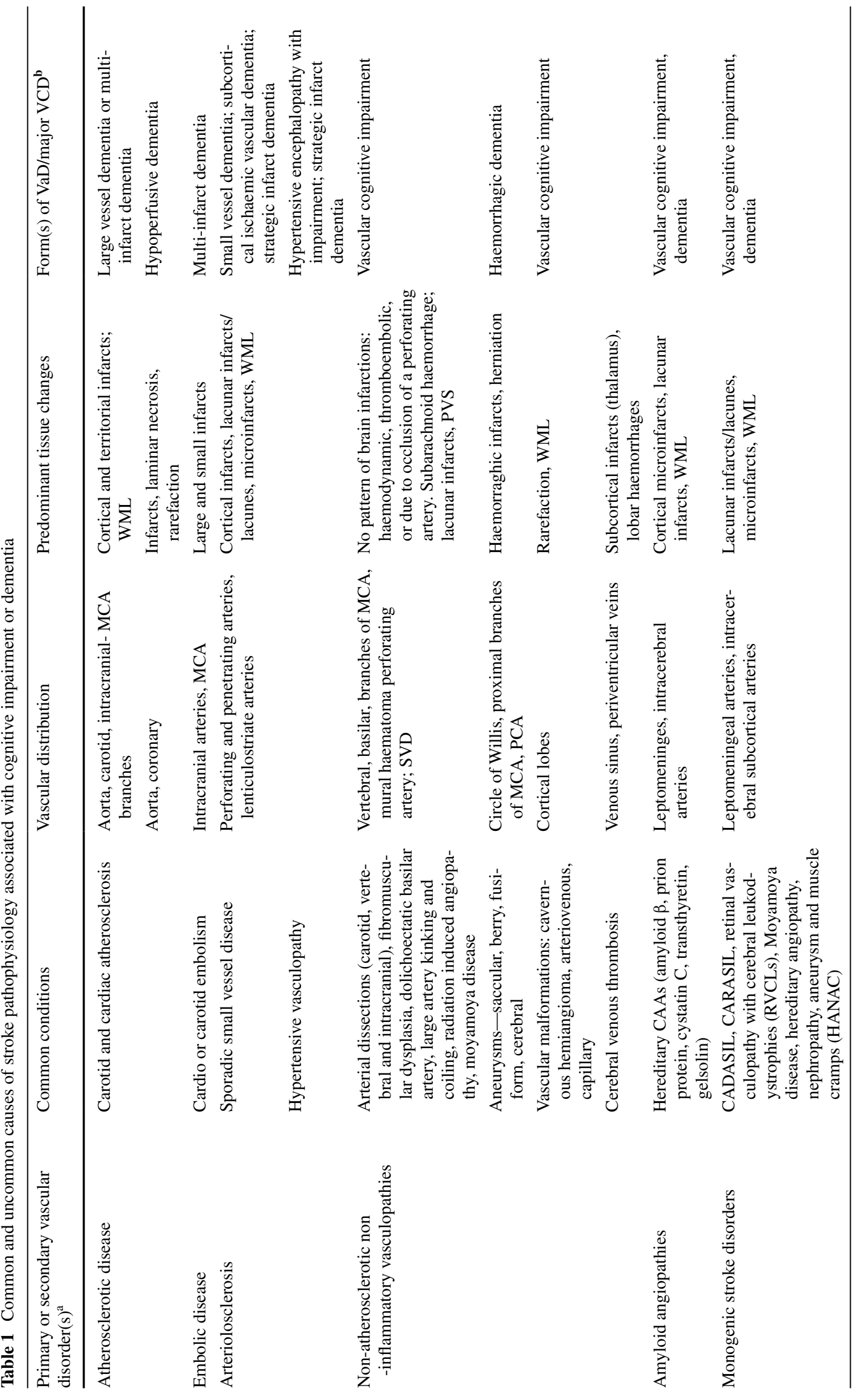




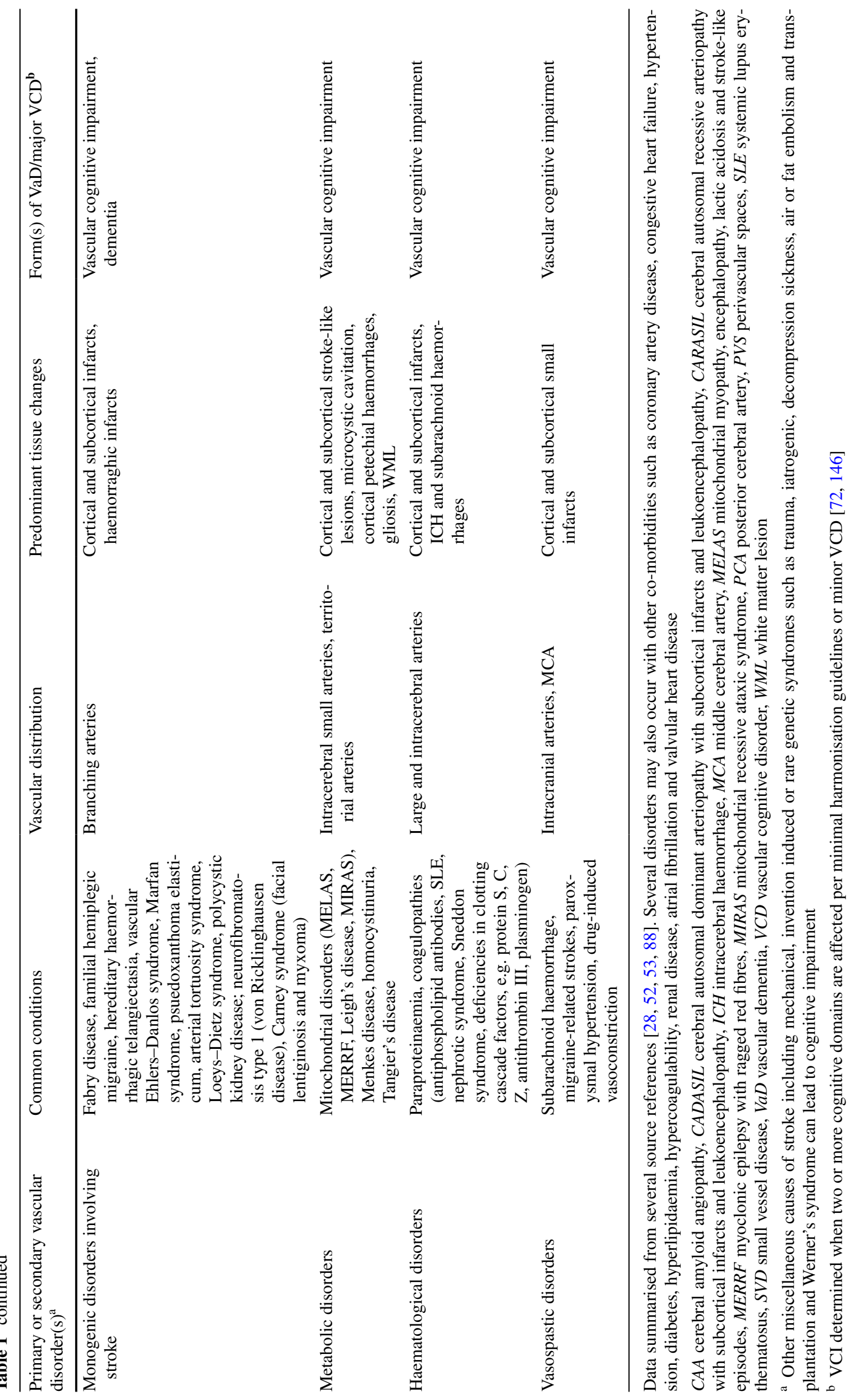


within 3 months or after a stabilisation period of a year or longer after stroke injury [4, 16, 133]. However, PSD can have a complex aetiology with varying combinations of large and SVD as well as non-vascular pathology. Stroke injury or CVD may unmask other preexisting disease processes such as AD. It has been recently demonstrated that at least $75 \%$ of PSD cases fulfilling relevant clinical guidelines for VCI are pathologically confirmed as VaD with little or no AD pathology [4]. Thus, most of PSD is VaD.

\section{Clinical information on vascular causes of dementia}

Review of the medical records of a patient who has died with CVD provides insight into the nature of clinical progression and identifies anatomical regions linked to any patterns of changes in cognition or behaviour. It also assists in planning extra histological sampling in addition to the standard brain cutting and sampling procedures (Table 2).
Table 2 Pathological lesions in CVD for neuropathology reporting

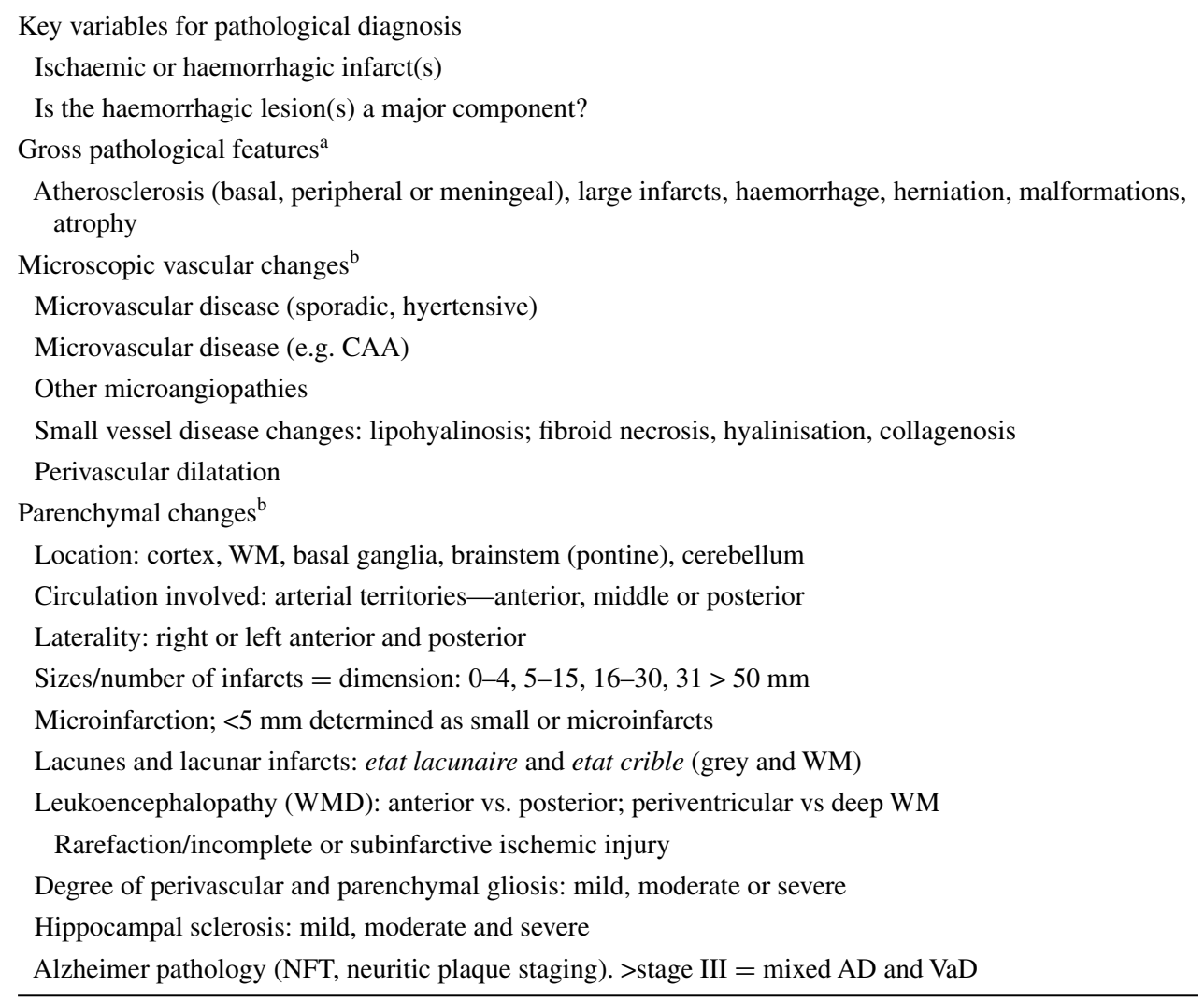

$C A A$ cerebral amyloid angiopathy, $C V D$ cerebrovascular disease, NFT neurofibrillary tangles, WM white matter, $W M D$ white matter disease

${ }^{a}$ Gross examination The protocol for examination of brains from CVD subjects is essentially similar to that for any other disease. The routine includes looking for sites and volumes of haemorrhages, herniation, malformations, swelling or oedema and atrophy. Any extradural, subdural or subarachnoid haemorrhage(s) that has occurred should be noted. There may be signs of ruptured aneurysms, cortical lacerations, burst intracranial haemorrhage and leakage of intraventricular haemorrhage through the cerebellar foramina. The basal cerebral arteries and vertebro-basilar arteries and the main branches can be checked for the degrees of atheroma and the presence of thrombosis. Open branch points, for example, at the trifurcation of the internal carotid and middle cerebral artery are common sites for emboli. Vascular abnormalities may include aneurysms, clips and endovascular coils and malformations. The leptomeninges should be assessed for thickness and translucency, which may be altered much with age

${ }^{b}$ For reporting purposes, each of the above features can be scored numerically to provide a summary [72]. For example, 0 is absent and 1 means present. Less frequent lesions including watershed infarcts and laminar necrosis. Increasing numerical value may also be assigned to the infarcts 
Strategies for the staged examination of the postmortem brain in suspected dementia have evolved over time with the increasing use of immunohistochemical and molecular tools for diagnosis. This has led to an expanding range of diagnostic categories (Table 1). In CVD cases, diagnostic imaging may have been performed that will also be useful for the diagnosis. However, clinical information plays an important role in the formulation of a clinicopathological summary. Thus, a number of questions should be considered: (1) How was the diagnosis of dementia made? (2) Was the assessment been made by a clinician experienced in dementia? (3) Have causes of secondary dementia been excluded? (4) Has there been longitudinal assessment of the patient with application of bedside tests of cognitive function? It is common for a diagnosis of dementia to be applied to an elderly subject who has delirium or is cognitively impaired because of an acute problem and is therefore best classed as having an acute confusional state? Depression may also lead to poor global performance and is a recognised cause of pseudo-dementia. Another question relates to the domains of cognition affected first. At the end stage of disease, it can be clinically difficult to discriminate between different diseases. The early clinical features obtained from medical records often give important clues to the subsequent pathological diagnosis for which the pathologist attempts to distinguish between the various clinico-anatomic syndromes [88]. Further specific questions concern neurological features associated with the decline in cognitive function that can be attributed to the cause of dementia.

\section{Neuropsychometric correlates of VCI and VaD}

Upon evaluation of clinical information including history, timing of event, neuropsychometry and neuroimaging of the DSM criteria are mostly widely applied to define the presence of dementia. In the DSM-IV and earlier versions of DSM criteria, diagnosis of dementia placed emphasis on memory loss as a core feature. However, many patients with $\mathrm{VaD}$ will not necessarily have profound memory deficits, particularly in the early stages. They predominantly develop a frontal dysexecutive syndrome [40]. This shortfall has been overcome in recently proposed guidelines for the diagnosis of minor and major vascular cognitive disorder, which concentrates on speed of information processing, complex attention and frontal-executive functioning [146]. Another advancement in this context is the use of the Montreal Cognitive Assessment (MoCA) as a preferred first cognitive screening instrument to challenge the wellestablished Mini-Mental State Exam (MMSE). Both the full and short versions of the MoCA appear to have excellent diagnostic accuracy in discriminating $\mathrm{VaD}$ patients in terms of sensitivity and specificity against the MMSE [58]. To define various cognitive domains for assessment of executive dysfunction including features such as processing speed, attention and reaction time, different centres use variations of established neuropsychometric batteries and tests such as the Automated Geriatric Examination for Computer-Assisted Taxonomy (AGECAT), Cambridge Cognitive Examination (CAMCOG), Cambridge Examination for Mental Disorders (CAMDEX), Cognitive Abilities Screening Instrument (CASI) and Mattis Dementia Rating Scale (MDRS), which are most often biased for AD (Table 3).

\section{Towards the diagnostic criteria for VaD}

In the past, several proposals were made to better define the diagnostic criteria for $\operatorname{VaD}[182,183]$. These have variable specificities and sensitivities and are not interchangeable with substantial misclassification of dementias [35, 62, 135]. The inclusion of deficits in certain cognitive domains such as memory, which is primary to $\mathrm{AD}$, concurs with the relatively low sensitivity $(0.20)$, but high specificity $(0.93)$ for probable $\mathrm{VaD}$ apparent in clinicopathological validation studies [62]. In earlier studies, the Hachinski Ischaemic Scale used was used to indicate the presence of multiinfarct dementia in demented patients who scored $\geq 7$ out of 10. Subsequent specific developments included the Alzheimer's Disease Diagnostic and Treatment Centers (ADDTC) criteria for ischaemic $\mathrm{VaD}$ [33], the National Institute for Neurological Disorders and Stroke-Association Internationale pour la Recherché et l'Enseignement en Neurosciences (NINDS-AIREN) criteria for VaD [144] and the International Classification of Diseases (ICD-10) criteria for VaD. The ADDTC followed by the NINDS-AIREN criteria for possible (ischaemic) VaD achieves the best balance of sensitivity and specificity with reasonable agreement with DSM-IV criteria for possible VaD. However, none of the criteria including the ADDTC, NINDS-AIREN and ICD-10 consistently revealed high sensitivity for probable VaD. Despite the deficiencies, the NINDS-AIREN criteria are still most widely used, particularly in research settings. The NINDS-AIREN criteria emphasise the heterogeneity of $\mathrm{VaD}$ syndromes and pathological subtypes (e.g. ischaemic and haemorrhagic strokes, cerebral hypoxic-ischaemic events, WM changes) [144]. The three cardinal features of VaD that harmonise with NINDS-AIREN criteria for the clinical diagnosis of probable VaD include (1) acute onset of dementia, demonstrated by impairment of memory and two other cognitive domains, such as orientation, praxis, or executive dysfunction, (2) relevant neuroimaging evidence of cerebrovascular lesions and (3) evidence for a temporal relation between stroke and cognitive loss [142]. Although neuroimaging evidence of vascular lesions is required for a 


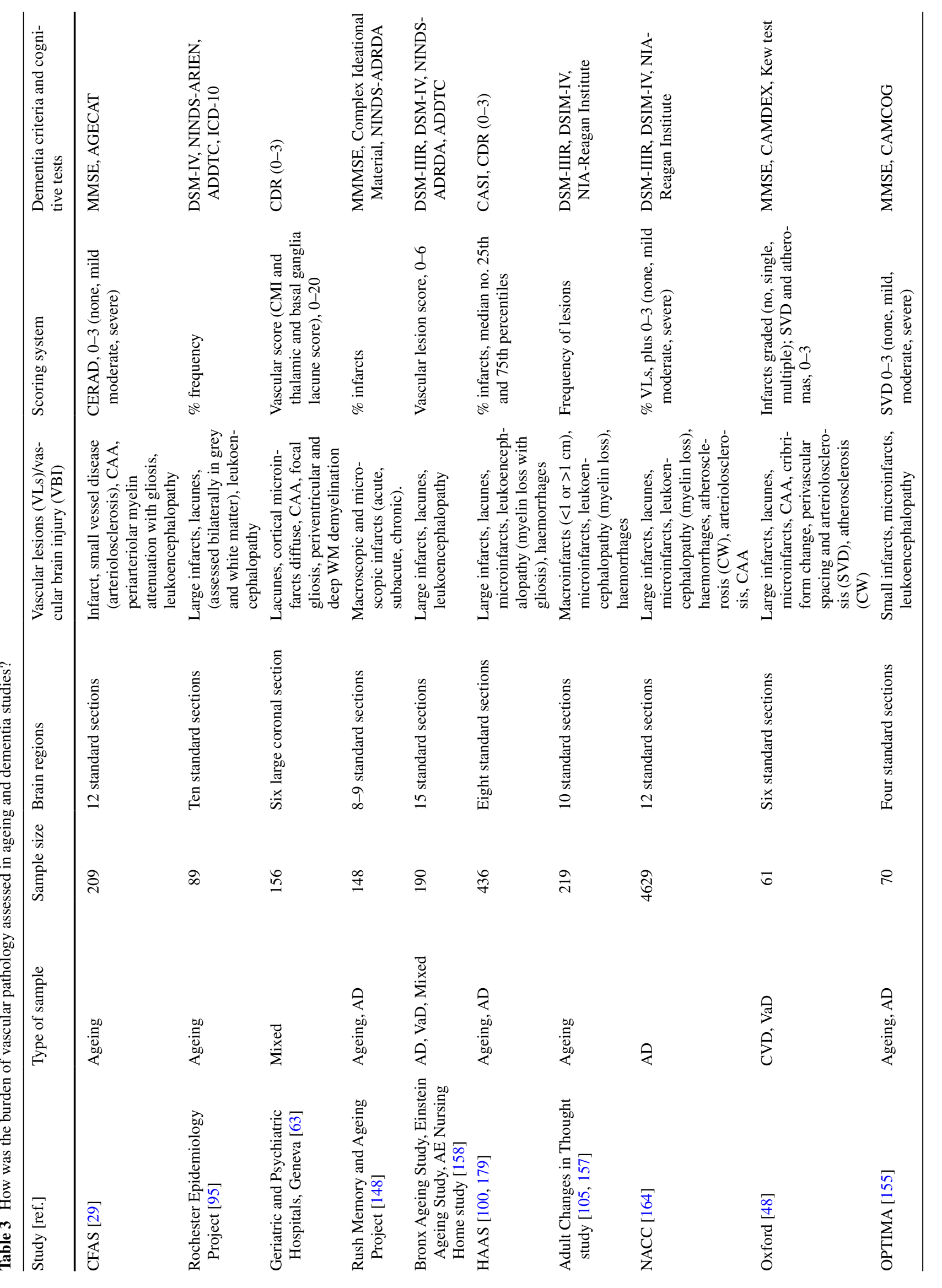




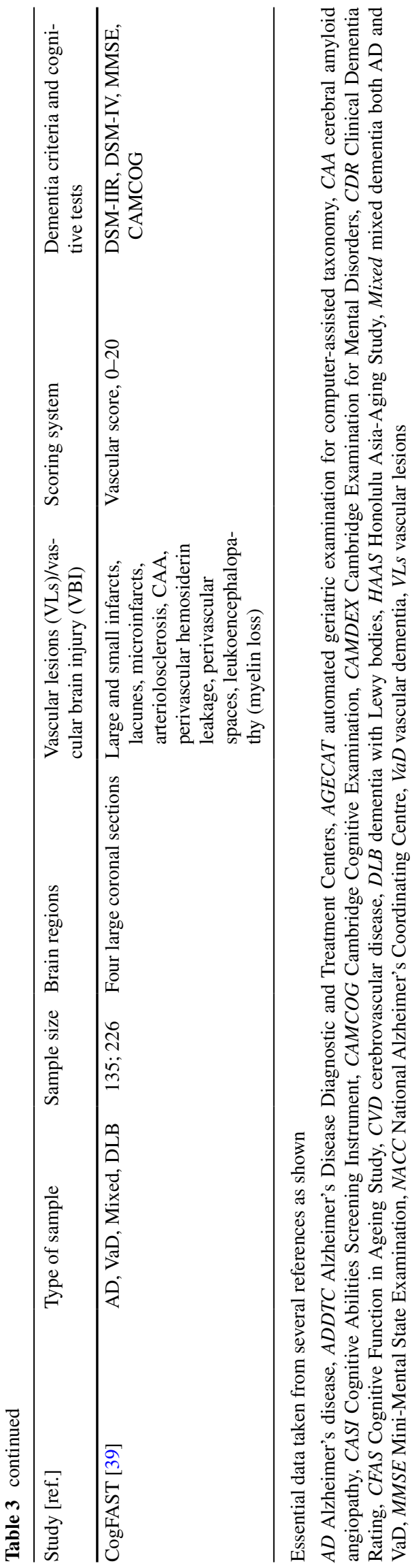

diagnosis of probable VaD, the NINDS-AIREN criteria do not distinguish between subjects with and without dementia in the context of CVD [11]. The diagnosis of 'definite' VaD requires histopathological evidence of CVD (Table 2), an absence of neurofibrillary tangles and neuritic plaques exceeding those expected for age and an absence of other conditions associated with dementia [90].

Despite the wide use of NINDS-AIREN and DSM-IV criteria, postmortem examination is not performed in general. However, when they do occur, inaccuracy of clinically diagnosed $\mathrm{VaD}$ is often revealed. Invariably, autopsy findings reveal subjects with $\mathrm{AD}$ type of pathological changes [45, 80, 87]. For example, a US study [117] reported that $87 \%$ of the patients enrolled in a prospective series to examine $\mathrm{VaD}$ in a dementia clinic setting were found to have $\mathrm{AD}$ either alone $(58 \%)$ or in combination with CVD (42\%). All of the patients with signs of CVD were also found to have some concomitant neurodegenerative disease. Similarly, another study indicated that large numbers of 'pure' $\mathrm{VaD}$ cases without co-existing neuropathological evidence of AD are uncommon [80]. This means that the current clinical diagnostic criteria are useful to detect pathology, but not necessarily "pure" pathology [79, 95]. There are currently no widely validated criteria for either VCI or vascular cognitive disorder [63, 72, 146]. Unbiased criteria encompassing relevant cognitive domains for VCI still need to be widely evaluated [39, 65, 72]. However, as with $\mathrm{AD}$, definitive diagnosis of $\mathrm{VaD}$ is made at autopsy, but appropriate sampling and essential neuropathological examination are necessary to rule out significant other pathological changes associated with different causes of cognitive impairment [72].

Several factors account for the difficulty in deriving an accurate diagnosis of $\mathrm{VaD}$. These include sampling bias, inadequate sample size and absence of pathological verification in many clinical studies; the use of non-standard or difficult-to-compare assessment instruments for clinical, neuropsychological, neuroimaging and neuropathological evaluation [72, 127]; and, equally important, disagreement over interpretation of data. More sensitive neuroimaging modalities have increased antemortem recognition of vascular changes in dementia patients, but these have also become harder to interpret, by revealing similar lesions in non-demented individuals. As discussed above, accurate diagnosis is also not straightforward given the heterogeneity of vascular lesions and the inherent issues with standardisation, especially when assessing mixed pathologies [63]. Depending on the inclinations of the observer, cases of AD with coexistent vascular lesions such as infarcts may be classified variously as $\mathrm{VaD}$, or $\mathrm{AD}$ with coexistent vascular pathology, or mixed dementia [55, 149]. To derive more accurate prevalence or incidence estimates and pathological diagnosis, uniformity in protocols and appropriate 
brain sampling at autopsy across different centres are necessary $[3,39,63,72,127,158]$.

\section{Clinicopathological correlation in VaD: past and present}

Although diagnostic criteria for the neuropathological validation of $\mathrm{VaD}$ are lacking, neuroimaging and clinicopathological studies have clearly indicated that the threshold for $\mathrm{VaD}$ depends on the extent of cerebral damage. A combination of factors including origin, volume, location and number of lesions contribute to the development of dementia. Tomlinson and colleagues had previously determined that the total volume of infarcts in demented stroke patients was usually over $50 \mathrm{~mL}$ and in some cases greater than $100 \mathrm{~mL}$, exceeding that in non-demented stroke patients [19, 165]. Subsequent clinicopathological studies reported that only 5 of 23 patients with a pathological diagnosis of $\mathrm{VaD}$ had more than $50 \mathrm{~mL}$ of infarcted tissue and 7 had less than $10 \mathrm{~mL}$ [45]. It is now clear that widespread small ischaemic lesions or multiple microinfarcts $[178,179]$ distributed throughout the CNS correlate better with dementia and are key predictors of cognitive impairment [86]. Location of lesions may also be more critical than total volume [41, 46]. For example, infarction in the left hemisphere disproportionately increases the risk of dementia [41, 64, 104, 134]. Bilateral infarcts with greater involvement of the dominant hemisphere also increase the risk of dementia after stroke [38, 45, 104].

Relatively few prospective studies have validated criteria for $\mathrm{VaD}$. Previous criteria for Binswanger's disease or cerebral SVD [17] proposed that the clinical diagnosis of dementia accompanied by neuroimaging evidence (CT or MRI) of bilateral abnormalities and at least two of three findings included evidence of (1) a vascular risk factor or systemic vascular disease, (2) focal cerebrovascular disease and (3) "subcortical" cerebral dysfunction described by gait disorder, parkinsonism, or incontinence. These criteria were validated in a prospective series of 184 patients with $\mathrm{AD}$ and showed that only $1.6 \%$ were diagnostically misclassified when all three clinical criteria were met [17].

The Oxford Project to Investigate Memory and Ageing (OPTIMA) study has recently developed a simple, novel, image-matching scoring system [155] to relate the extent of SVD with cognitive function in a study of 70 cases with insufficient pathology to meet the criteria for the diagnosis of AD. The severity of SVD pathology was inversely related to cognitive scores and $43 \%$ of the cases with high SVD scores were designated as being demented. To better define clinicopathological correlation in subtypes of VaD including SVD, a staging system related to the natural history of cerebrovascular pathology and an algorithm for the neuropathological quantification of the CVD burden in dementia have been proposed [39]. The staging system (I-VI) needs further evaluation against cognitive function scores to determine whether this system can be used in large-scale studies to understand the clinicopathological correlations.

Neuropathological diagnosis of $\mathrm{VaD}$ should be based on the absence of a primary neurodegenerative disease known to cause dementia and the presence of cerebrovascular pathology that defines one or more of the VaD subtypes (Table 1). These would also include dementia among post-stroke survivors who fulfill the NINDS-AIREN criteria [144] for probable VaD. Stroke survivors with mild cognitive impairment or VCI [118] may also have sufficient pathology for neuropathological diagnosis of $\mathrm{VaD}$ [4]. A proposal for the neuropathological diagnostic evaluation of $\mathrm{VaD}$ was previously published by the Newcastle investigators (Fig. 1). According to these criteria, there are two neuropathological diagnostic groups: probable $\mathrm{VaD}$ is based on the exclusion of a primary neurodegenerative disease known to cause dementia plus the presence of cerebrovascular pathology that defines one or more of the VaD subtypes. Possible VaD is designated when the brain contains vascular pathology that does not fulfill the criteria for one of the subtypes, but where no other explanation for dementia is found. Post-stroke survivors are often classed as subtypes I-III. Cases with extensive WM disease in the absence of other significant pathologies are included under SVD.

Assessing the neuropathological substrates of $\mathrm{VaD}$ involves systematic assessment of parenchymal lesions, including microinfarcts and haemorrhages and the vascular abnormalities that may have caused them to relate to the progression of impairment [39, 90, 110, 155, 158]. In addition, systemic factors (e.g. hypotension, hypoglycaemia) may cause brain or neuronal lesions in the absence of severe vascular disease and should be taken into account when attributing causes to $\mathrm{VaD}$. As discussed above, parenchymal abnormalities of neurodegenerative type may be present that are not obviously associated with either vascular disease or systemic factors, i.e. Alzheimer type or hippocampal lesions.

\section{Frequency of pathologically diagnosed VaD}

Confirmation of $\mathrm{VaD}$ diagnosis is definitive at autopsy derived from appropriate sampling of both cerebral hemispheres and neuropathological examination [72] to rule out significant pathological changes associated with other dementias. The prevalence of early-onset dementia $\mathrm{VaD}$ ( $<65$ years old) ranges from 3.1 to $44 \%$ in various clinic and population-based studies across the world [172]. 


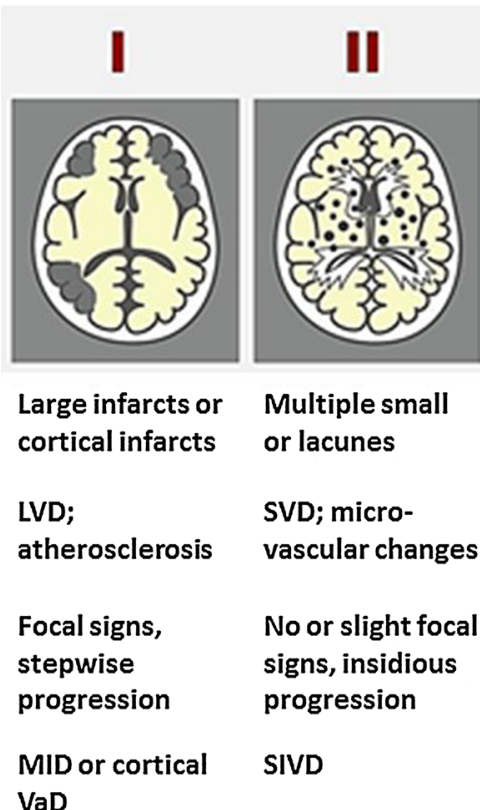

VaD

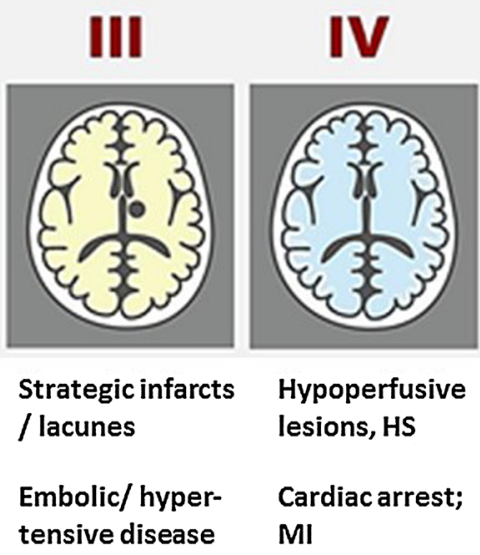

Focal signs, stepwise progression

Strategic

infarct dementia
Fig. 1 Schematic diagram of different cerebrovascular pathologies associated with dementia. The proposed Newcastle categorisation includes six subtypes [90]. In all the above, the age of the vascular lesion(s) should correspond with the time when the disease began. The post-stroke survivors are usually included in subtypes I-III. While these may not be different from other published subtypes [84], they are practical and simple to use. Cases with extensive WM disease in the absence of significant other features are included under SVD. *Subtype $I$ may result from large vessel occlusion (atherothromboembolism), artery to artery embolism or cardioembolism.

However, these values may not reflect the true prevalence and incidence rates of $\mathrm{VaD}$ due to inconsistencies in diagnostic criteria, sampling methods and subject or country demographics and variation in morbidity and mortality trends. When a range of clinical criteria was applied to sample sizes of 59-1929, autopsy studies showed that pathologically diagnosed $\mathrm{VaD}$ ranges widely from as low as $0.03 \%$ to as high as $58 \%$ with an overall mean estimate of $17 \%$ [84]. In Western countries, the estimated rates of pathologically diagnosed $\mathrm{VaD}$ as defined by various criteria lie between 8 and $15 \%$. In studies where diagnosis was restricted to the currently used NINDS-AIREN criteria [144], the frequencies are reported to be $\sim 7 \%$. Taking the above estimates into consideration, the worldwide frequency of $\mathrm{VaD}$ in autopsy-verified cases is calculated to $10-15 \%$, being marginally less than when clinical criteria alone are used $[13,95]$. In Japan, the incidence of autopsy-verified $\mathrm{VaD}$ was previously $35 \%$ [150] and later reported to be $22 \%$ [1]. Population-based cohorts should provide the best estimates for pathology-verified $\mathrm{VaD}$. However, there are only few such studies and they all show that microvascular lesions occur more frequently than

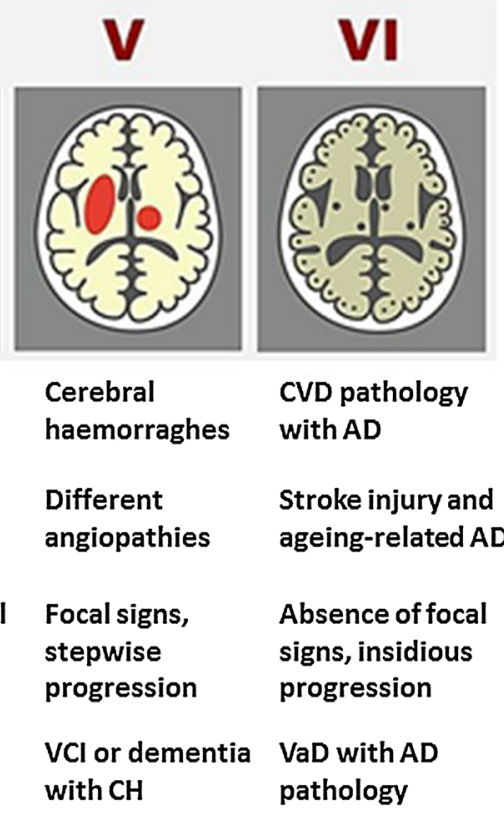

Subtype II usually involves descriptions of arteriosclerosis, lipohyalinosis and hypertensive, arteriosclerotic, amyloid or collagen angiopathy. Subtypes $I, I I$ and $V$ may result from aneurysms, arterial dissections, arteriovenous malformations and various forms of arteritis (vasculitis). $A D$ Alzheimer's disease, $C H$ cerebral haemorrhage, $C V D$ cerebrovascular disease, $M I$ myocardial infarction, $M I D$ multi-infarct dementia, $L V D$ large vessel disease, SIVD subcortical ischaemic vascular dementia, $S V D$ small vessel disease, $V C I$ vascular cognitive impairment, $V a D$ vascular dementia

neurodegenerative lesions in elderly community-dwelling subjects with dementia $[29,148,157,181]$.

\section{Sampling and investigation of the brain}

Some form of CVD is common among the assortment of all routine autopsies. Stroke is the most frequent CVD disorder with more than 200 causes. Stroke-related injury may comprise microscopic lesions such as microinfarcts and microhaemorrhages to large cortical infarcts and lobar haemorrhages (Table 1). Recent advances in neuroimaging and systematic neuropathological examination have enabled better definitions of clinically diagnosed CVD, which causes cognitive impairment [72]. The pathological diagnosis of $\mathrm{VaD}$ or VCI, however, requires the systematic evaluation of potentially relevant clinical or phenotypic features with particular attention to the timing of events [88]. It is difficult to define which neuropathological changes and to what degree these contribute to dementia because of the heterogeneous localisation of lesions and the co-existence of other pathologies including neurodegenerative changes 
such as those in $\mathrm{AD}$. More than one factor may contribute to the overall impairment and the $\mathrm{VaD}$ phenotype (Table 1). These include the origin and type of vascular occlusion, presence of haemorrhage, distribution of arterial territories and the size of vessels involved. Thus, many brain regions including the territories of the anterior, posterior and middle cerebral arteries, the angular gyrus, caudate and medial thalamus in the dominant hemisphere, the amygdala and hippocampus, as well as the hippocampus have been implicated in VaD. Factors that define pathology in subtypes of $\mathrm{VaD}$ include multiplicity, size, anatomical location, laterality and age of the lesions besides genetic influences and previous existence of systemic vascular disease. Subcortical ischaemic $\mathrm{VaD}$ is likely the most significant subtype of $\mathrm{VaD}$ [142] and smaller subcortical lesions seem to be key players (Table 2).

Gross external examination of the brain at autopsy is extremely useful for a quick indication of the presence of cerebrovascular pathology (Table 2). As is widely practiced, the brain from CVD cases is cut in the coronal plane throughout. This is irrespective of whether fresh samples are dissected for freezing at autopsy or the brain is immersion fixed for later sectioning. In Newcastle, brains from CVD cases are sliced fresh in the coronal plane and then alternate sections from each hemisphere are retained as
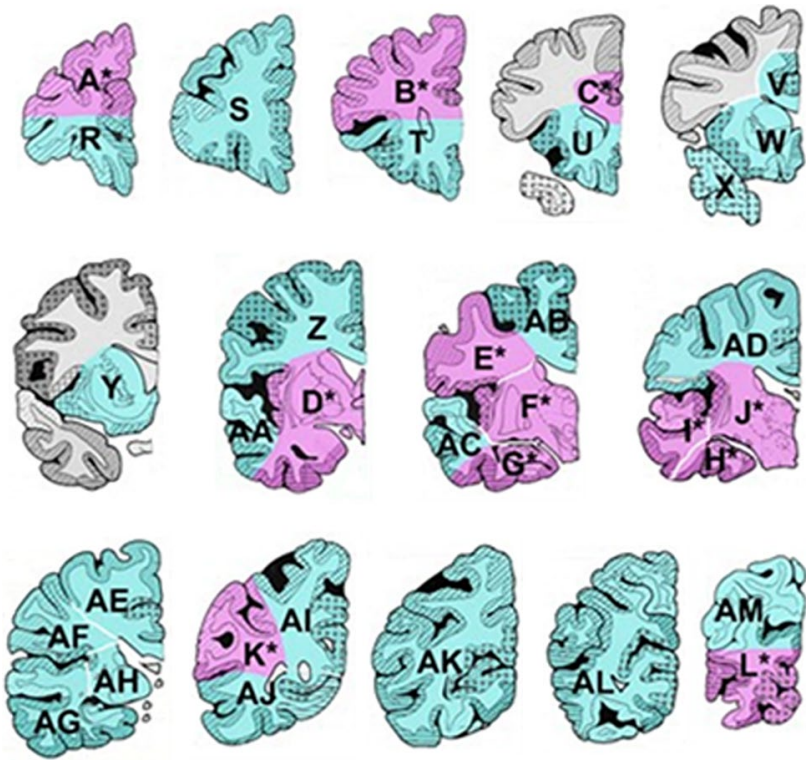

Fig. 2 Sampling of postmortem brain tissue for assessing vascular pathology. Coronal blocks from one hemisphere (rostral to caudal) of the cerebrum for an 'ideal' sample for neuropathological assessment. In Newcastle, large sections are taken as indicated by the pink and green blocks identified by the letters. A minimum sample constituting four to six large blocks including $\mathrm{S}, \mathrm{Y} / \mathrm{W}, \mathrm{F} / \mathrm{J}, \mathrm{G} / \mathrm{H}, \mathrm{AB} / \mathrm{AD}$ and $\mathrm{AL}$ can be reliably used to determine the burden of vascular pathology [39] fixed or frozen material, which is deposited in the Newcastle Brain Tissue Resource. While unconventional, it has been the normal practice for the past 30 years in Newcastle to sample large sections (average size $6 \times 5 \mathrm{~cm}$ ) for better appreciation of pathology, but this is not necessarily the case in many laboratories (Fig. 2).

What is the best strategy for brain sampling? Various recommendations for brain region sampling and histological evaluation in a stratified fashion have been made (Table 2). Block sampling is recommended from the middle frontal gyrus, superior and middle temporal gyri, inferior parietal lobule and occipital cortex; in addition, the medulla, pons (including locus coeruleus), cerebellar cortex (including dentate nucleus), thalamus and subthalamic nucleus, basal ganglia at the level of the anterior commissure, hippocampus and entorhinal cortex, anterior cingulate gyrus and amygdala $[81,111]$ may also be considered. The BrainNet Europe Consortium has previously recommended a sampling strategy that may be adapted for instances when consent is not available to retain the whole brain for diagnostic evaluation [2]. While these are biased towards neurofibrillary pathology and involve sections from the occipital cortex, superior and middle temporal gyrus, anterior hippocampus and/or amygdala and posterior hippocampus at the level of the lateral geniculate body, they are not ideal or sufficient for scoring vascular pathology. The minimal sample set for scoring vascular pathology would include sections of the frontal lobe at the level of the olfactory bulbs, the temporal lobe at the level of the anterior hippocampus and the basal ganglia (lenticular nucleus and anterior thalamus) at the level of the mamillary body [39]. The posterior hippocampus is included if available. These regions represent relevant cerebral systems involved in cognition and receive blood from each major cerebral arterial supply [39]. The National Institute on Aging-Alzheimer's Association (NIA-AA) recommends the assessment of hippocampal sclerosis, vascular brain injury and microvascular lesions in 12 regions [81]. However, as correctly recommended by the BrainNet Consortium [3], a simple strategy regarding assessment of load of alteration is urgently needed to yield reproducible and, at the same time, comparable results between centres.

At most centres, the histological evaluation of vascular pathology or brain tissue injury is undertaken in a rather subjective manner and is remarkably variable (Table 3 ). Degrees of vessel, e.g. arteriosclerosis and tissue changes (vascular brain injury) in terms of infarcts and rarefaction, often reported as a composite semi-quantitative score, are noted to validate the clinical picture. This is probably adequate for routine neuropathology reporting taking into account the nature and extent of specific changes in the vascular anatomy and the parenchyma (Table 2). More rigorous and objective analysis is time consuming and tedious 
and is more suitable for research purposes. However, various methods for more accurate determination have been used to quantify the vascular pathology. Table 4 provides the details of various methods which can be implemented for quantification of vascular and relevant cellular changes.

\section{Cerebrovascular pathology and brain parenchymal changes}

Atherosclerotic and embolic disease are the main causes of infarctions associated with major arterial territories, which may be admixed in the cortical and subcortical regions [70] (Table 1). Thromboembolic events are responsible for up to $50 \%$ of all ischaemic strokes, whereas intracranial SVD causes $25 \%$ of the infarcts. Small vessel alternations involve arteriolosclerosis and hyalinosis and associated with lacunar infarcts predominantly occurring in the WM, basal ganglia and thalamus. WM disease or subcortical leukoencephalopathy with incomplete infarction is a common pathological change associated with dementia [39]. Other features include border zone (watershed) infarctions, laminar necrosis and cerebral amyloid angiopathy (CAA). Complicated angiopathies such as fibromuscular dysplasia, arterial dissections, granulomatous angiitis, collagen vascular disease and giant cell arteritis are rarer causes of CVD and $\mathrm{VaD}$ (Table 1).

Few studies have recorded precise ischaemic, oedematous and haemorrhagic lesions induced by pathological changes in the brain circulation or perfusion to be associated with $\mathrm{VaD}$ (Table 2). In ten different studies where $\mathrm{VaD}$ was diagnosed, clinically, $78 \%$ of the cases revealed cortical and subcortical infarcts suggesting that other vascular pathologies involving incomplete infarction or border zone infarcts could be important factors. Among other lesions $25 \%$ of the cases had cystic infarcts whereas $50 \%$ showed lacunar infarcts or microinfarcts. Lacunar infarcts, however, appear to be a common category of infarcts and currently recognised as the most frequent cause of stroke (Table 2). Severe CAA was present in $10 \%$ of the cases. Hippocampal sclerosis and cell atrophy, which may be caused by remote ischaemic injury, was apparent in $55 \%$ of the cases in one study with clinical diagnosis of ischaemic VaD [173]. In an attempt to evaluate the natural history and staging of CVD, Deramecourt et al. [39] proposed that vessel wall modifications such as arteriolosclerosis or CAA were the most common and earliest changes. These were followed by perivascular spacing with lacunar and regional microinfarcts infarcts occurring as consequent, but independent processes. The regional progression of the changes were frontal $>$ temporal lobe $\geq$ basal ganglia. In dementia subjects, VaD had the highest total scores of vascular pathology, whereas AD was the second and dementia with Lewy bodies was the last but greater than in ageing controls [39].

\section{Interaction between vascular and Alzheimer type of pathologies}

Concurrent CVD is a common neuropathological finding in aged subjects with dementia and more common in $\mathrm{AD}$ than in other neurodegenerative disorders, especially in younger subjects. This is evident not only in samples from memory clinics we first evaluated over 20 years ago [136], but also in those from large multicentre studies [164]. In the National Alzheimer's Coordinating Centre minimum data set sample of 4429 clinically diagnosed AD cases, the presence of CVD and any vascular pathology was reported to be 32 and $80 \%$ respectively. Approximately, $20 \%$ of these had lacunes and microinfarcts [164]. The admixture of CVD pathology and neurodegenerative changes particularly neurofibrillary and $\alpha$-synuclein pathologies is even greater in elderly people within the community at large [29, 140, 157]. The co-occurrence of CVD lowers the threshold for dementia caused by a single neurodegenerative process. In one community-based sample, $38 \%$ of dementia cases had mixed pathology, with both Alzheimer-type changes and vascular lesions, but 'pure $\mathrm{AD}^{\prime}$ represented only 21-24\% of the cases [148]. WM lesions indicating ischaemic or oligaemic aetiology are also high in communitydwelling subjects by as much as $94 \%$, and this change is an independent substrate for dementia [50]. In addition, atherosclerosis in cerebral arteries and the circle of Willis [141, 187] is frequently present in AD. The commonest overlapping pathologies involve smaller cerebrovascular lesions rather than large infarcts [39] (Fig. 3). These include most features of SVD such as cortical infarcts, lacunes, diffuse and periventricular myelin loss, WM microvacuolation, microinfarcts, microhaemorrhages, arteriolosclerosis and focal and diffuse gliosis [10, 48, 173]. AD pathology was found to be three times greater in $\mathrm{VaD}$ cases with small $(<15 \mathrm{~mL})$ compared to large infarcts [10]. The findings also corroborate the importance of microvascular disease rather than large vessel disease as the critical substrate in $\mathrm{VaD}$ and AD.

Clinicopathological studies also suggest that vascular disease not only influences the burden of the neurodegenerative lesion [140, 190]. The density of neocortical plaques was lower in $\mathrm{AD}$ cases with coexistent vascular lesions interpreted as contributing to dementia [113]. In the Religious Order study, elderly nuns who exhibited coexistent $\mathrm{AD}$ and brain infarcts at autopsy had poorer cognitive function and a higher prevalence of dementia than those without vascular change [156]. Compared with pure $\mathrm{AD}$, the lower burden of Alzheimer-type pathology, particularly fewer 


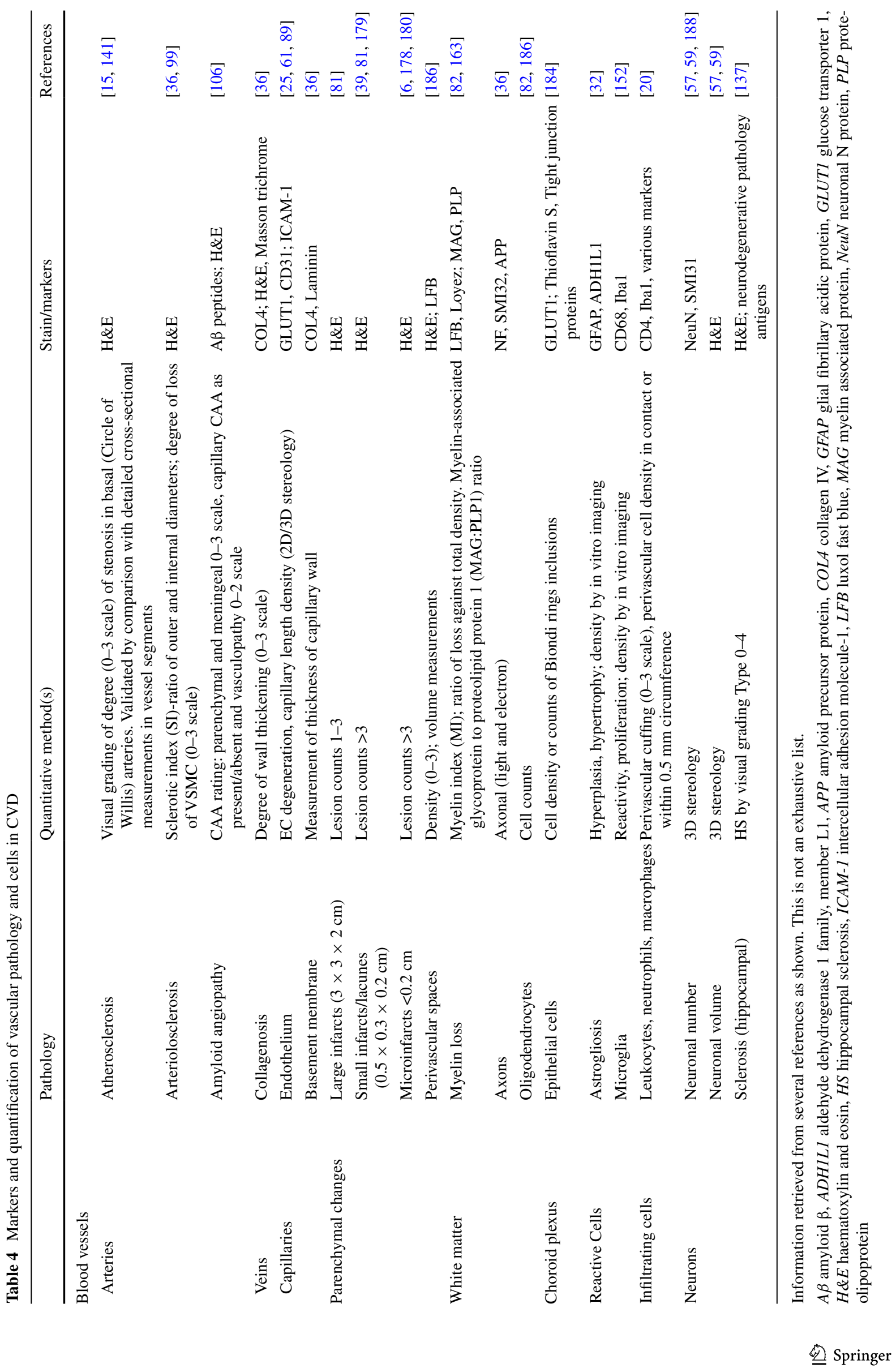




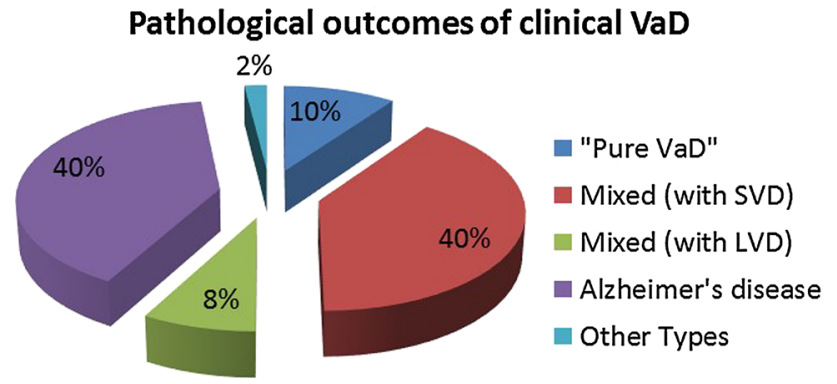

Fig. 3 Pathological outcomes of clinically diagnosed VaD. Mixed type 1 revealed large infracts, whereas mixed type 2 predominantly exhibited SVD with microinfarction. Other included Lewy body disease, dementia, mild Parkinson disease and depression. $A D$ Alzheimer's disease

neurofibrillary tangles, was required to reach the threshold for dementia when there were concomitant lacunar infarcts in subcortical structures including the basal ganglia, thalamus or deep WM. Similarly, in another religious order study, after accounting for AD lesion burden, the presence of other pathologies or infarcts increased the odds of dementia over fivefold [148] and caused earlier onset of dementia [47].

\section{Pathology of extra- and intracranial large vessels}

Large infarction or macroinfarction should be visible upon gross examination of the brain at autopsy. Stenosis arising from atherosclerosis within large vessels is considered the main cause of large infarction, which may sometimes extend beyond the arterial territories. The stages of atherosclerosis may vary from accumulation of foam cells causing fatty streaks to complicated atheromas involving extracellular matrix components and even viral or bacterial infections [88]. Approximately, $15 \%$ of $\mathrm{VaD}$ assumes occlusion of the extracranial arteries such as the internal carotid artery and the main intracranial arteries of the circle of Willis including the middle cerebral artery, leading to multiple infarcts and dementia [24]. The differences between the anterior versus posterior portions of the circle of Willis and left versus right sides may be variable, and stenosis of major arteries could be up to $75 \%$ in very severe cases. Typical atherosclerosis or microatheromatous disease in the meningeal and smaller vessels, beyond the circle of Willis involving the proximal segments of the middle and anterior cerebral arteries, is generally rare, but may be found in very old subjects [91]. The presence of dolichoectasia and fusiform aneurysms has also been noted in some cases. In severe cases, medium-sized arteries in the leptomeninges and proximal perforating arteries are involved. The damage could be worse depending on the presence of hypertension.
Arterial territorial infarctions involve four principal areas, particularly those supplied by the major arteries: anterior, middle cerebral artery, posterior artery and the territory between the anterior and middle cerebral artery. The intensity of gliosis, both astrocytic and microgliosis, is an important consideration in judging the degree and age of infarction. However, there is no clear evidence to suggest these are related to cognitive impairment. Degrees of gliosis or glial scars are noted in brains subjected to global ischaemia, i.e. after transient cardiac arrest where responses may be observed in vulnerable neuronal groups within the hippocampus or neocortical laminae.

\section{Small cerebral vessels}

SVD entails fibroid necrosis, hyalinisation of vessels, expansion of the perivascular space and pallor of adjacent perivascular myelin, with associated astrocytic gliosis (Fig. 4). The smaller vessels of the brain including intracerebral end arteries and arterioles undergo progressive age-related changes [99], which alter perfusion and cause lacunar infarcts (cystic lesions generally $<1 \mathrm{~cm}$ ) and microinfarcts. The arteriolar changes range from wall thickening by hyalinosis, reduction or increment of the intima to severe arteriolosclerosis and fibroid necrosis. Arteriolosclerotic changes likely promote loss of elasticity to dilate and constrict in response to variations of systemic blood pressure or auto-regulation, which in turn causes fluctuations in blood flow response and changes in tissue perfusion. The deep cerebral structures and WM would be rendered most vulnerable, because the vessels are end arteries almost devoid of anastomoses. Small vessel pathology could also lead to oedema and damage of the blood-brain barrier (BBB) with chronic leakage of fluid and macromolecules in the WM [61, 78, 175]. Microvascular disease may also be associated with degrees of inflammation including the presence of lymphocytes or macrophages localised on blood vessels (and not necessarily a function of brain ischaemia). In the oldest SVD subjects, there may also often be evidence of remote haemorrhage in the form of perivascular hemosiderin [39].

\section{Lacunar infarction}

Lacunar infarcts, about $1 \mathrm{~cm}$ or less in diameter, may occur as complete or cavitating lesions frequently in both subcortical grey and WM in VaD. They represent small foci of ischaemic necrosis resulting from narrowing or occlusion of penetrating arteries branching directly from larger cerebral arteries [56]. Lacunar infarcts are frequently multiple and bilateral and often coexist with other vascular lesions 

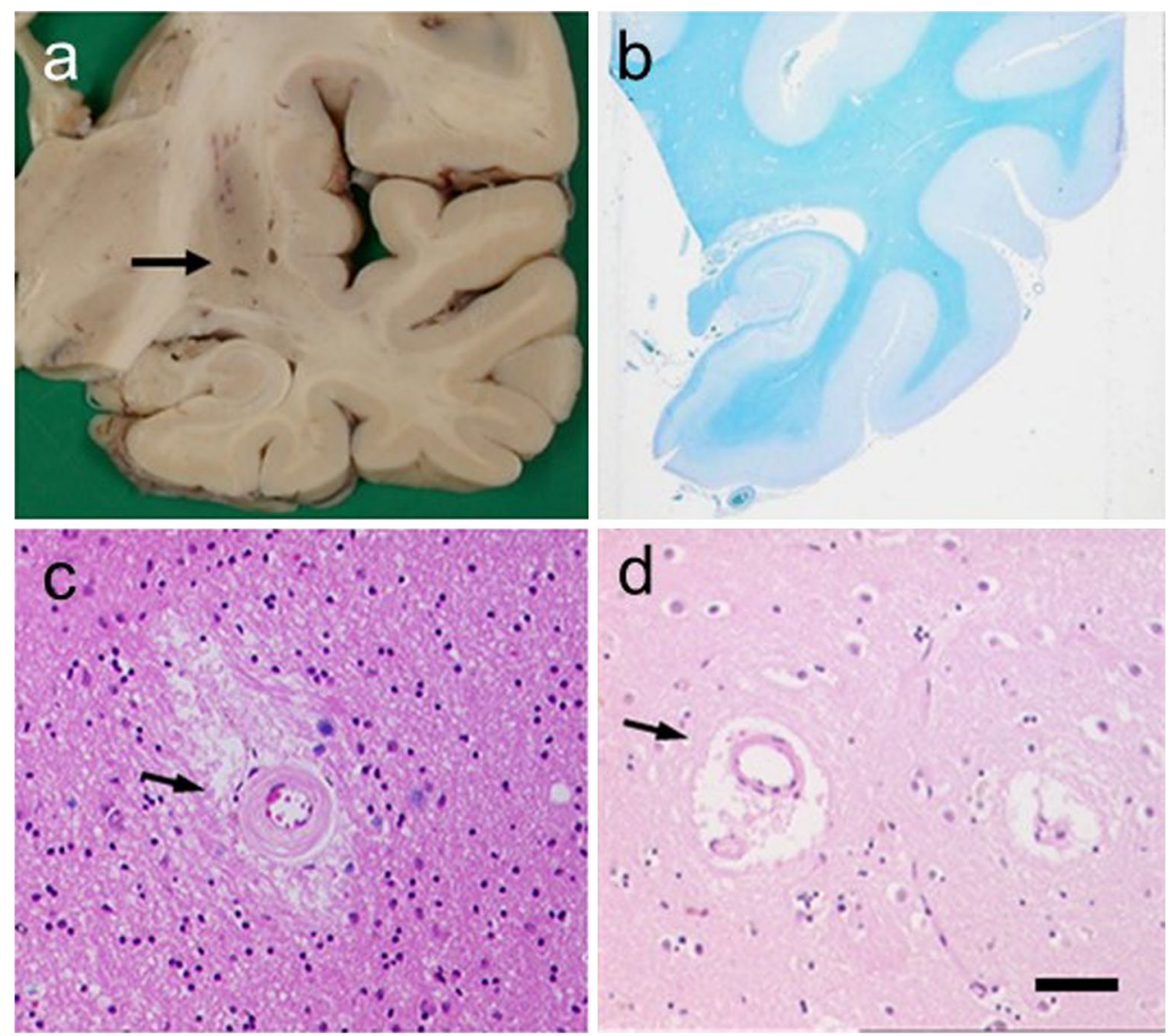

Fig. 4 Pathological features associated with SVD in VaD. Panels show examples of lacunes, small infarcts and microinfarcts. a Typical cavitated lacunar lesions (arrow) in the putamen of a 65-year-old man. b WM attenuation in the medial temporal lobe, but sparing of U fibres. Section from an 80-year-old man with vascular and neurofi-

(e.g. large infarcts or diffuse WM damage). Whether single or multiple, they may be asymptomatic, depending on their location and the volume of normal brain tissue lost. Lacunes may also represent small haemorrhages or dilated perivascular spaces without infarction or haemorrhage. A few lacunes may represent healed or re-absorbed as minute or petechial haemorrhages. Microlacunes have also been described which essentially should be thought of as large cystic microinfarcts.

Apart from critical lesions occurring often in the internal capsule or caudate nucleus, recent meta-analyses suggested there were no pathological differences between symptomatic and asymptomatic patients. Perivascular oedema and thickening, and inflammation and disintegration of the arteriolar wall were common, whereas vessel occlusion was rare [9], In neuropathological studies of elderly patients with vascular disease but without evidence of $\mathrm{AD}$ or other neurodegenerative pathologies, dementia was associated brillary pathology. c, d Cerebral microvessels with variable hyalinosis, perivascular rarefaction, microinfarcts and perivascular spaces in two different cases. Moderate gliosis in the surrounding region is also evident in the case in c. d Perivascular dilatation (or spacing) in the WM (arrow). Magnification bar a $1 \mathrm{~cm}, \mathbf{b} 500 \mu \mathrm{m}, \mathbf{c}, \mathbf{d} 100 \mu \mathrm{m}$

with severe cribriform change and associated subcortical WM damage and microinfarcts [48, 158]. In the Honolulu-Asia Aging Study (HAAS) analysis [179], microvascular infarcts (lacunar and microinfarcts) were identified as the sole or dominant lesion in $34 \%$ of the definitely impaired decedents. Only leukoencephalopathy was associated with dementia, and large infarcts were associated with $\mathrm{VaD}$. $\mathrm{VaD}$ without significant $\mathrm{AD}$ pathology shows more severe cribriform change and deep white and grey matter lacunar or microinfarcts than stroke subjects with macroscopic infarcts and elderly subjects without dementia [155]. Similarly, lacunar infarcts and microinfarcts were the most common neuropathological features in more than $50 \%$ of elderly patients with ischaemic $\mathrm{VaD}$ [173] and also strong determinants of dementia in the Geneva brain ageing study [60]. However, all these findings were also often accompanied by moderate to severe atherosclerosis. 


\section{White matter changes}

White matter hyperintensities on T2-weighted MRI or leukoaraiosis as a decreased signal on computed tomography (CT) is a neuroimaging construct to describe diffuse and focal WM changes. Leukoariaosis predominantly has reference to vascular disease. It not only incorporates WM rarefaction, incomplete infarction, lacunar strokes, perivascular spacing and demyelination, but sometimes also axonal degeneration (Figs. 4 and 5). Both, areas of leukoaraiosis and zones outside the lesions show decreased vascular density indicating that leukoaraiosis appears as a generalised feature of CVD rather than being limited to the deep WM. This is consistent with the finding of an association of unstable carotid plaques with the number of WM lesions, suggesting a thromboembolic role in some patients with leukoaraiosis [5].

Neuroimaging and pathological studies demonstrate that WM hyperintensisties represent degeneration of the WM mostly explained by SVD [125, 126, 158]. Diffuse and focal WM lesions are a hallmark of VaD [82], but also occur most in $\sim 30 \%$ of AD and dementia with Lewy body (DLB) cases [44]. There is some controversy whether deep or periventricular lesions are of more importance, but this depends on the definition of boundaries between the periventricular and deep WM if the coursing of the fibres is used as markers [96]. Lacunar infarcts are produced when the ischaemic damage is focal and of sufficient severity to result in a small area of necrosis, whereas diffuse WM change is considered a form of rarefaction or incomplete infarction where there may be selective damage to some cellular components. Although the $\mathrm{U}$ fibres are frequently spared WM disease may comprise several patterns of alterations including pallor or swelling of myelin, loss of oligodendrocytes, damage to axons, cavitations with or without the presence of macrophages and areas of reactive astrogliosis [152], where the astrocytic cytoplasm and cell processes may be visible with standard stains. Oligodendrocytes are particularly vulnerable to hypoxic environment created by low perfusion, which in turn may differentially affect myelin as indicated by the remarkable reduction in the ratio of myelin-associated glycoprotein (MAG) to proteolipid protein 1 (PLP1) not only in the WM, but also the cerebral cortex in $\operatorname{VaD}[12,163]$.

Lesions in the WM also include spongiosis, i.e. vacuolisation of the WM structures and widening of the perivascular spaces [186]. The affected regions do not have sharp boundaries, in contrast to the plaques of multiple sclerosis. These changes may be associated with chronic pro-thrombotic endothelial dysfunction in cerebral SVD [77] also involving the WM [23]. There may be a cerebral response to the SVD by increasing endothelial thrombomodulin [61]. The projected misery perfusion due to capillary loss or abnormalities occurring prior to leukoaraiosis corroborates the finding of a chronic hypoxic state in the deep WM [51], which also releases several growth promoting factors [153]. Some of the WM damage in demented patients may simply reflect Wallerian changes secondary to cortical loss of neurons. However, histological changes characteristic of Wallerian degeneration are not readily evident as WM pallor. Conversely, in AD patients with severe loss of cortical neurons, similar WM lesions are not apparent [44].

While WM changes focus on the arterial system, narrowing and, in many cases, occlusion of veins and venules by collagenous thickening of the vessel walls also occur. The thickening of the walls of periventricular veins and venules by collagen (collagenosis) increases with age, and perivenous collagenosis is increased further in brains with leukoaraiosis [22]. The presence of apoptotic cells in WM
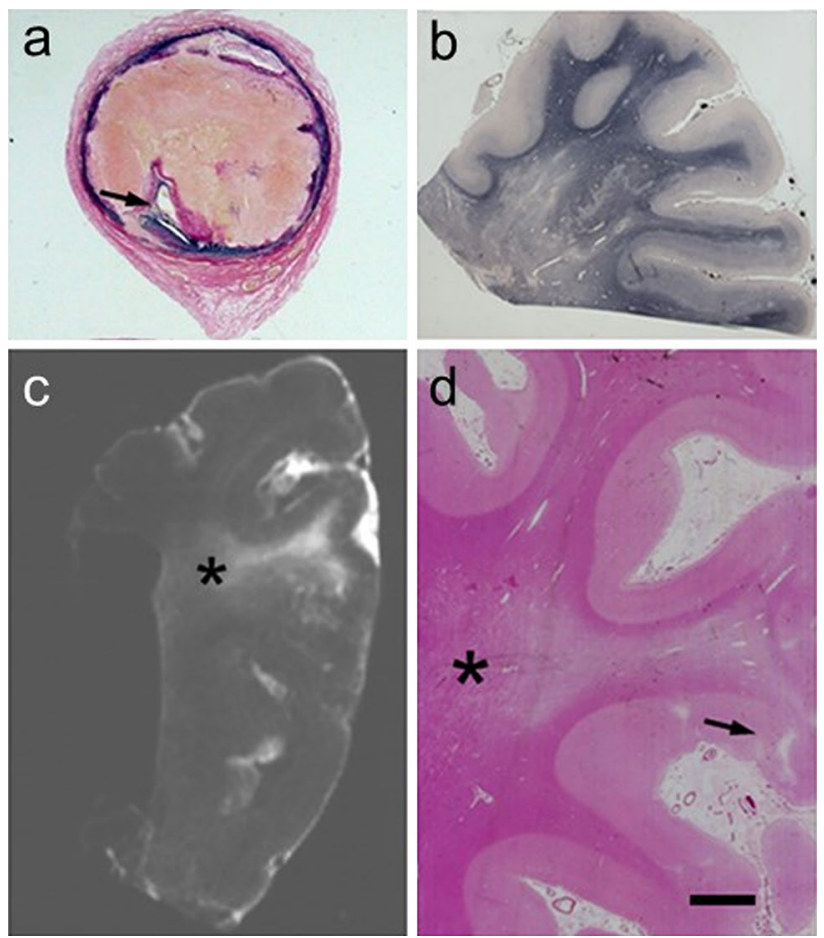

Fig. 5 WM lesions visualised by conventional histopathological staining in a 69-year-old man diagnosed with vascular encephalopathy (and $\mathrm{VaD}$ ). a $>75 \%$ stenosis in the internal carotid artery $8 \mathrm{~mm}$ above the bifurcation. The narrowed lumen (arrow) is seen. b Severe WM changes in the parietal lobe in this patient. Braak staging was graded as IV, but there were no neuritic or cored plaques. c Postmortem T2W magnetic resonance image of a formalin-fixed block from the parietal lobe. The area of hypersignal can be seen in the WM (asterisk). d H\&E stained section from the block in c showing severe deep WM pallor in the area of hypertensity (asterisk). A small cortical infarct is also seen (arrow). Magnification bar a $500 \mathrm{~mm}, \mathbf{b}$ $400 \mu \mathrm{m}, \mathbf{c} 1 \mathrm{~cm}, \mathbf{d} 500 \mu \mathrm{m}$ 
adjacent to areas of leukoaraiosis suggests that such lesions are dynamic, with progressive cell loss and expansion [22]. Vascular stenosis caused by collagenosis may induce chronic ischaemia or oedema in the deep WM leading to capillary loss and more widespread effects on the brain [23].

\section{Cerebral microinfarction}

The accumulation of small, even miniscule ischaemic lesions as an important substrate of $\mathrm{VaD}$ has been emphasised in recent years [86]. Microinfarcts are widely accepted to be small lesions visible only upon microscopy (Fig. 4; Table 3). These lesions of up to $5 \mathrm{~mm}$ diameter may or may not involve a small vessel at its centre, but are foci with pallor, neuronal loss, axonal damage (WM) and gliosis. They are estimated to occur in thousands [178]. Sometimes these may include regions of incomplete infarction or rarefied (subacute) change. Microinfarcts have been described as attenuated lesions of indistinct nature occurring in both cortical and subcortical regions. Such lesions or a combination of these are reported when there are multiple or at least greater than three present in any region (Table 2). Microvascular infarcts (lacunar infarcts and microinfarcts) appear central to the most common cause of $\mathrm{VaD}$ (Fig. 4) and predict poor outcome in the elderly [10, 21, 173]. Interestingly, in the autopsied older HAAS, the importance of microvascular lesions as a likely explanation for dementia was nearly equal to that of Alzheimer lesions $[179,180]$. Microinfarction in the subcortical structures has been emphasised as a substrate of cognitive impairment $[6$, 86] and correlated with increased Alzheimer type of pathology, but cortical microinfarcts also appear to contribute to the progression of cognitive deficits in brain ageing [97].

In addition to microinfarction in the subcortical structures, it appears increasingly important that multiple cortical areas of microinfarction are associated with subcortical VaD or SVD (Fig. 4). Thus, these lesions should be taken into account when defining the neuropathological criteria. Cortical microinfarcts are increased in the presence of CAA [121] (Fig. 6). In a recent study, cortical microinfarcts were frequently detected in $\mathrm{AD}$ and associated with CAA, but rarely observed in subcortical VaD linked to SVD [120, 159]. Microinfarcts in the cerebral cortex associated with severe CAA may be the primary pathological substrate in a significant proportion of $\mathrm{VaD}$ cases [74]. Cortical microinfarcts and to lesser extent periventricular demyelination were significantly associated with cognitive decline in individuals at high risk for dementia [63]. It is proposed the changes in hemodynamics, e.g. hypotension and atherosclerosis may play a role in the genesis of cortical watershed microinfarcts.

\section{Large and small cerebral haemorrhages}

Cerebral microbleeds detected by MRI are small, dot-like hypotense abnormalities, have been associated with extravasated haemosiderin derived from erythrocytes, lipohyalinosis and CAA [49]. They are likely a surrogate marker of SVD evident on MRI along with lacunes and WM changes [168]. The prevalence of radiological microbleeds in $\mathrm{VaD}$ ranges 35-85\%. Microbleeds are mainly thought to result from hypertensive vasculopathy, but the frequent co-occurrence of lobar microbleeds suggests that the neurodegenerative pathology or CAA is also of importance [177]. The relevance of this radiological construct is increasingly recognised due to their relation to clinical outcome and occurrence in anti-amyloid vaccination trials [69]. However, the presence of multiple microbleeds in the context of $\mathrm{VaD}$ is related to worse performance on cognitive tests, mainly in psychomotor speed and executive functioning. Since microbleeds are common in cognitively normal older individuals, attribution of these to $\mathrm{VaD}$ should follow a careful exclusion of other causes of cognitive impairment and only if numerous such lesions are present.

Both radiological cerebral microbleeds and foci of haemosiderin containing single crystalloids or larger perivascular aggregates are found in brains of older subjects including those diagnosed with $\mathrm{VaD}$ and $\mathrm{AD}$, but the radiological and pathological relationship between these findings has not been entirely clear. Recent evidence suggests that cerebral microbleeds detected by MR imaging are a surrogate for ischaemic SVD rather than exclusively haemorrhagic diathesis [83]. Greater putamen haemosiderin was significantly associated with indices of small vessel ischaemia, including microinfarcts, arteriolosclerosis and perivascular spacing and with lacunes in any brain region but not large vessel disease, or whole brain measures of neurodegenerative pathology. Higher levels of putamen haemosiderin were correlated with more microbleeds upon MR imaging, but it is possible that brain iron homoeostasis and small vessel ischaemic change are responsible for these rather than only as a marker for minor episodes of cerebrovascular extravasation.

\section{Hippocampal atrophy and sclerosis}

Neuroimaging studies have shown that medial temporal lobe and hippocampal atrophy are associated with $\mathrm{VaD}$ [14, 54] and SVD [119, 167], albeit not to the same extent as in AD [26]. Pathological evidence shows that ischaemic VaD and SVD are also associated with hippocampal changes and atrophy remote to ischaemic injury $[108,188]$. Hippocampal neurones in the Sommer's sector are highly vulnerable to disturbances in the cerebral circulation or hypoxia caused by systemic vascular disease. The focal 

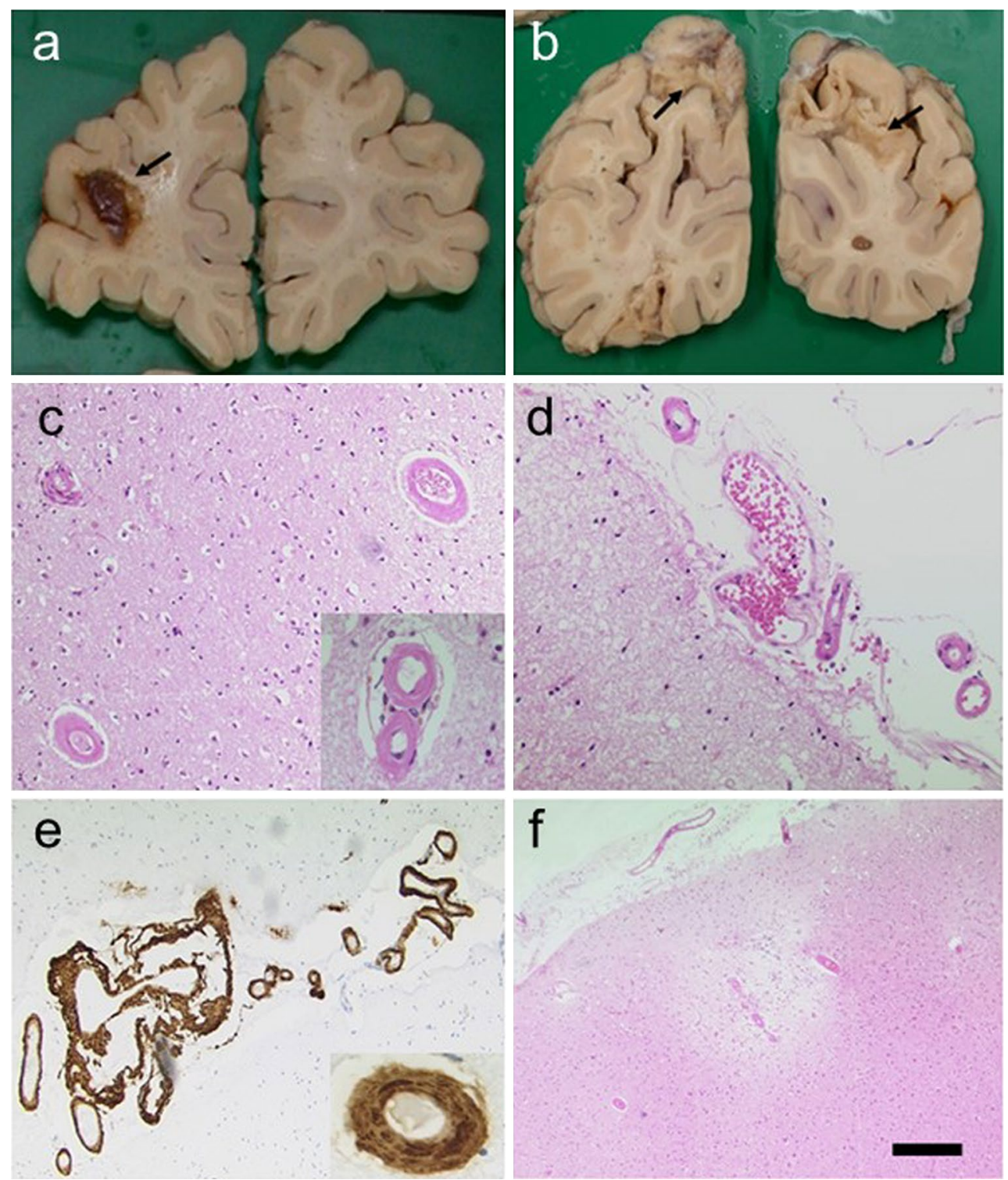

Fig. 6 CAA and infarcts in a 92-year-old woman with memory loss, confusional state and disorientation. CT on admission showed infarction in the right posterior parieto-occipital region. Small lacunar infarct in the posterior aspect of the left corona radiata, probable area of cortical infarction in the left occipital lobe. a Lobar haemorrhage in the frontal lobe. b Macroscopical cortical infarcts in both right and left occipital lobes. c, d Cortical and subarachnoidal arterioles

loss of CA1 neurons in ischemic $\mathrm{VaD}$ has been related to lower hippocampal volume and memory score [188], but the degree of loss appears less in $\mathrm{VaD}$ [98] than in $\mathrm{AD}$. However, selective hippocampal neuronal shrinkage is also an important substrate for $\mathrm{VaD}$. This is also evident in delayed dementia after stroke in the absence of any neurodegenerative pathology [59]. Thus, there is a clear vascular basis for hippocampal neurodegeneration and concurs with the neuroimaging observations of hippocampal atrophy even in population-based incident $\mathrm{VaD}$ [147]. The simplest

showing thickened homogenous eosinophilic walls. Inset in c, two strongly stained eosinophilic vessels. e A $\beta$ immunohistochemistry shows extensive subarachnoidal and cortical amyloid angiopathy. f A cortical microinfarct with haemosiderin. There were numerous microinfarcts in the frontal, parietal and occipital cortices. Subject only showed sparse cored and diffuse senile plaques and Braak stage II for neurofibrillary pathology. Magnification bar a, b $1 \mathrm{~cm}, \mathbf{c}-\mathbf{f} 100 \mu \mathrm{m}$

mechanistic explanation for the atrophy is that the neuronal or dendritic arbour results in subsequent loss in connectivity, which contributes to brain structural and functional changes. This is consistent with the finding that soluble synaptophysin was decreased in $\mathrm{VaD}$ as well as $\mathrm{AD}$.

Hippocampal sclerosis is a likely a major contributing factor in the hippocampal atrophy and occurs in approximately $10 \%$ of individuals over the age of 85 years and slightly higher in $\mathrm{VaD}$. It is characterised by severe cell loss with the CA fields in the presence or absence of microinfarction 
and gliosis that is not explained by AD. TAR DNA protein 43 immunohistochemistry can be used to demonstrate that hippocampal sclerosis, regardless of accompanying pathologies (e.g. AD or vascular), is consistent with an underlying neurodegenerative pathogenetic mechanism [189]. Any focal loss or patterns of hippocampal sclerosis can be graded [137] and recorded together with any microinfarctions. Sometimes, the patchy neuron loss and gliosis in some brains with AD pathology may be difficult or impossible to distinguish from anoxic-ischemic change. The aetiology of hippocampal sclerosis is defined in association with a neurodegenerative process, a pathologic condition presumed to arise from hypoxic/ischemic mechanisms [137]. Hippocampal sclerosis pathology can be associated with different underlying causes, but a large study [115] found no evidence for associations between hippocampal sclerosis and lacunar infarcts, large infarcts, Circle of Willis atherosclerosis or CAA. However, there was a correlation between hippocampal sclerosis and arteriolosclerosis in multiple brain regions outside of the hippocampus including the frontal cortex (Brodmann area 9) [115]. This is ascribed to a pathogenetic change in aged human brain arterioles that impacts multiple brain areas and contributes to hippocampal sclerosis of ageing [116].

\section{Border zone and watershed infarcts}

The border zone or watershed infarctions mostly occur from haemodynamic events, usually in patients with severe internal carotid artery stenosis. They could occur bilaterally or unilaterally and disposed to regions between two main arterial territories, deep and superficial vessel systems. Typical border zone infarctions may be $5 \mathrm{~mm}$ or more wide as wedge-shaped regions of pallor and rarefaction extending into the WM. Larger areas of incomplete infarction may extend into the WM [82]. These are characterised by mild to moderate loss of oligodendrocytes, myelin and axons in areas where there may be hyalinised vessels [24]. This may be accompanied by astrogliosis, some microgliosis and macrophage infiltration. The morphology of incomplete or subinfarctive changes, though suspected to be associated with cognitive function, is not consistently described in $\mathrm{VaD}$. It may variably manifest as tissue rarefaction assessed by conventional stains and revealed as injury response such as microgliosis and astrocytosis, or the presence of other "reactive" cells or surrogate markers of dendritic, synaptic or axonal damage.

\section{Laminar necrosis}

Laminar necrosis is characterised by neuronal ischaemic changes leading to neuronal loss and gliosis in the cortical ribbon. This is particularly apparent in cases where global ischaemia or hypoperfusion has occurred as in cardiac arrest. Typical topographic distribution of spongiform change can be readily apparent with standard stains. They appear more commonly at the arterial border zones [24, 88] that may fall into the subtype IV of VaD pathology.

\section{Sporadic cerebral amyloid angiopathy in VaD}

CAA occurs most commonly in $\mathrm{AD}[8,31,70,106]$, but it often occurs in CVD in the absence of Alzheimer pathology [34]. CAA is an independent substrate for cognitive impairment and contributes to cognitive dysfunction [7, 131]. Tissue microstructural damage caused by CAA prior to preintracerebral haemorrhage is also independently associated with cognitive impairment [174]. The prevalence of CAA in $\mathrm{VaD}$ is not known, but it is a major cause of intracerebral and lobar haemorrhages leading to profound ischaemic damage [138] (Fig. 6). Several familial forms of CAA involving ischaemic and haemorrhagic infarcts (see below) and cerebral hypoperfusion demonstrate the link between CAA and VaD. In a study of surgical biopsies exhibiting cerebral and cerebellar infarction, CAA was significantly more common in samples showing infarction than in agematched controls with non-vascular lesions [27]. There is also an association between severe CAA and cerebrovascular lesions coexisting with $\mathrm{AD}$, including lacunar infarcts, microinfarcts and haemorrhages [43, 121, 122]. This association apparently is not attributable to apolipoprotein $\mathrm{E}$ $(A P O E) \varepsilon 4$ allele, as the vascular lesions correlated best with severity of CAA, regardless of genotype [70, 123]. There is also some evidence to suggest that CAA is related to WM changes, but not exclusively in the oldest old [160]. The first stroke-like episode triggers multiple cerebral bleeds, which is preceded by diffuse WM changes that in turn lead to rapid decline of cognitive functions.

\section{Neurochemical pathology of VaD}

The neurochemical basis of cognitive decline in CVD is poorly understood. There are few concerted studies on the protein and lipid chemistry of VaD. Various cellular signalling and regulatory mechanisms including apoptosis, autophagy, oxidative stress and inflammation are associated with $\mathrm{VaD}$ by virtue of their involvement in cerebral ischaemia or oligaemia. VaD subjects also mount a selectively attenuated neuroinflammatory response [112]. It was reported that the monocyte chemoattractant protein- 1 and interleukin-6 concentrations were significantly reduced in the frontal lobe of $\mathrm{VaD}$ and mixed dementia subjects, 
suggesting that these changes had a vascular basis rather than due to Alzheimer pathology.

The perivascular nerve plexus [75] is highly vulnerable, yet only few transmitter-specific changes reflecting neurovascular pathology have been described in subtypes of $\mathrm{VaD}$. Selective transmitter specific changes have been described in some cases of $\mathrm{VaD}$ [87]. Two different groups had previously shown that compared to AD patients, choline acetyltransferase activity was also reduced albeit to a lesser degree in the temporal cortex and hippocampus in patients diagnosed with multi-infarct dementia or $\mathrm{VaD}[66$, 130]. Furthermore, choline acetyltransferase activities were significantly reduced by $60-70 \%$ in the frontal and temporal cortices of subjects with CADASIL, which models SVD [92]. Choline acetyltransferase and P75 (neurotrophin receptor) immunoreactivities were also affected within the cholinergic cell bodies of the basal forebrain in CADASIL, but these were not so pronounced. This may depend on the severity of the WM degeneration [92, 107]. However, loss of cholinergic function is consistently greater in $\mathrm{VaD}$ patients with concurrent Alzheimer pathology [143]. Conversely, a novel increase in cholinergic activity in the frontal cortex was revealed in infarct dementia [151].

Other studies have reported deficits in monoamines including dopamine and 5-hydroxytryptamine (5HT) in the basal ganglia and neocortex in $\mathrm{VaD}$ [66]. To compensate for the loss [42], 5-HT(1A) and 5-HT(2A) receptors are likely increased in the temporal cortex in multi-infarct, but not subcortical VaD. Such findings, albeit fragmentary, reveal distinctions between the neurochemical pathology of $\mathrm{VaD}$ subtypes and suggest possibilities of pharmacological manipulation with novel therapies in $\mathrm{VaD}$. There was also loss of glutamatergic synapses, assessed by vesicular glutamate transporter 1 concentrations, in the temporal cortex of $\mathrm{VaD}$ [93], but preservation of these in the frontal lobe suggests a role in sustaining cognition and protecting against dementia following a stroke. However, a recent study has shown that the presynaptic synaptic proteins synaptophysin and SNAP-25 are reduced, whereas drebrin is increased possibly due to decreased synaptic input in $\mathrm{VaD}$ [154]. Identification of the morphological equivalents of these changes in types of pyramidal cells in the frontal lobe would be relevant.

\section{Pathological investigation of hereditary CAA}

There are more than ten different hereditary CAAs caused by mutations in different genes $[139,185]$. All these angiopathies lead to some degree of cognitive impairment or

Table 5 Sampling of tissue and fluids for diagnosis of uncommon causes of CVD

\begin{tabular}{lll}
\hline Diagnostic sample & Diagnostic test & Target diagnoses \\
\hline Tissue biopsy & Arterial & Temporal or giant cell arteritis, Sneddon syndrome \\
& Cerebral meninges & Primary cerebral vasculitides \\
& Muscle & CADASIL, mitochondrial diseases \\
& Skin & CADASIL, CARASIL, Sneddon syndrome, psuedoxanthoma \\
& GLA activity & elasticum and unexplained skin lesions with CNS manifestations \\
CSF & Inflammatory cells & Fabry disease \\
Viral, bacterial & Vasculitides, sarcoidosis, CNS infections \\
& ANA, ENA and anti DNA & Specific infections \\
& antibodies, complement & Systemic lupus erythematosus, connective tissue diseases \\
& Protein electrophoresis & \\
Hb electrophoresis & Paraproteinaemia \\
& Toxicology & Sickle cell anaemia (HbS), thalassaemia \\
& Ammonium & Illicit drug use \\
& Lactic acidosis & Glutaric acidaemia type 1 and 2, urea cycle disorders \\
& Thrombophilia & Branch-chained organic acidurias, glutaric acidaemia \\
& type 1 and 2, mitochondrial diseases
\end{tabular}

Data adapted from several references $[88,161]$. Other rare conditions with stroke injury such as syphilis, systemic vasculitides and rheumatic diseases may also be diagnosed from CSF

ANA antinuclear antibodies, ENA extractable nuclear antigens, CADASIL cerebral autosomal dominant arteriopathy with subcortical infarcts and leukoencephalopathy, CARASIL cerebral autosomal recessive arteriopathy with subcortical infarcts and leukoencephalopathy, $C N S$ central nervous system, $C S F$ cerebrospinal fluid, GLA galactosidase alpha, $H b$ haemoglobin, MTHRF methylenetetrahydrofolate reductase 
dementia. They are characterised by multiple haemorrhages and haemorrhagic or ischaemic infarcts in addition to severe amyloid deposition within walls of the meningeal and intracerebral vessels. In hereditary cerebral haemorrhage with amyloidosis of the Dutch type, dementia occurs in most patients surviving their initial stroke [71] and may occasionally be the presenting feature [176]. The extensive CAA is alone sufficient to cause dementia and this has implications for CAA-related cognitive dysfunction in sporadic CAA and AD [114]. In the Icelandic type of hereditary cerebral haemorrhage with amyloidosis (HCHWA-I), which is associated with a point mutation in the gene encoding the cysteine protease inhibitor Cystatin C [101], dementia, occurring in some patients, has been attributed to the multiple vascular lesions. Individuals with gelsolin-related amyloidosis manifest facial palsy, mild peripheral neuropathy and corneal lattice dystrophy; atrophic bulbar palsy, gait ataxia and mild cognitive impairment [94]. Familial British dementia with severe CAA [170] is characterised by dementia, progressive spastic tetraparesis and cerebellar ataxia, the onset of which is usually in the sixth decade [109]. Neuropathological features also include Alzheimer-type neurofibrillary tangles and neuropil threads in the anteromedial temporal lobe that may contribute of dementia [132, 139]. Familial Danish dementia (FDD), also known as heredopathia ophthalmo-oto-encephalica, is another condition with severe and widespread CAA [171]. FDD is characterised clinically by cataracts, deafness, progressive ataxia and dementia.

\section{Investigation of familial small vessel diseases}

Several familial stroke disorders also appear to cause cognitive impairment or dementia. These can be diagnosed in biopsy tissues using immunohistochemical or electron microscopy methods (Table 5). A common feature in these is subcortical SVD, often characterised by severe arteriolosclerosis in the perforating vessels [185]. Cerebral autosomal dominant arteriopathy with subcortical infarcts and leukoencephalopathy (CADASIL) is the most common form of hereditary SVDs [30]. Motor deficits, an ataxic hemiparesis, hemianopsia and dysarthria may present as key neurological features akin to SVD. Vascular changes including apoptotic loss of brain vascular smooth muscle cells [68] and vessel wall thickening [37] likely reduce blood flow and affect the vasodilatory response to cause lacunar infarcts and microinfarcts in grey matter and WM [185]. The extensive demyelination and axonal damage in the underlying WM contributes to cortical atrophy [37] and impacting on frontal lobe cognitive functions that is consistent with the disconnection of the fronto-striatal circuits in CADASIL. Neuronal apoptosis, predominantly in neocortical layers III and V, also likely contributes to dementia in CADASIL [68].

The Maeda syndrome or cerebral autosomal recessive arteriopathy with subcortical infarcts and leukoencephalopathy (CARASIL) is an autosomal recessive disorder similar to CADASIL [76]. The normotensive affected subjects exhibit not only severe arteriolosclerosis, leukoencephalopathy and lacunar infarcts, but also spinal anomalies and alopecia. Strokes lead to stepwise deterioration with most subjects becoming demented in older age. Familial cerebral SVDs involving progressive visual impairment [185] cause deterioration in cognitive function. Hereditary endotheliopathy with retinopathy, nephropathy and stroke (HERNS), cerebroretinal vasculopathy (CRV) and hereditary vascular retinopathy (HVR) were reported independently, but represent different phenotypes in the same disease spectrum [85, 124, 162]. These, now described as autosomal dominant retinal vasculopathy with cerebral leukodystrophy, lead to early death and cause dementia. Retinal microvessels undergo severe distortions and become tortuous, predictive of the SVD type of pathology with multilaminated vascular basement membranes in the brain [85].

Some rarer and less characterised hereditary SVDs (Table 1) also exist that are associated with clinical SVD features and different degrees of cognitive impairment, but the pathologies in these are not described. They include conditions with abnormalities in the skin and eye and multiple lacunar infarcts in the deep WM and pons [128], retinal arteriolar tortuosity and leukoencephalopathy $[67,166]$ and profound WM changes upon MRI [169].

\section{Summary}

Defining the neuropathological substrates of $\mathrm{VaD}$ relies on uniformity in sampling and careful pathological examination. VaD resulting from severe VCI or vascular cognitive disorder or from delayed impairment after stroke appears to result from the accumulation of several lesions including cerebral atrophy. While robust neuropathological criteria for $\mathrm{VaD}$ are still being developed, multiple microinfarcts, small infarcts or lacunes in the subcortical structures rather than macroinfarction or large vessel disease appear most robustly related to cognitive impairment. Diffuse WM changes involving periventricular and deeper regions are frequent in $\mathrm{VaD}$. Concomitant hippocampal pathology including sclerosis and Alzheimer pathology compound disease progression. Further definitions of the neuropathological correlates of $\mathrm{VaD}$ and investigation of genetic models would be valuable for exploring the pathogenesis as well as management of $\mathrm{VaD}$ through preventative and treatment strategies. 
Acknowledgments This report was inspired at the British Neuropatholgy Society Summer School on Cerebrovascular Disorders, 2015. I am very grateful to Roxana Carare for promoting and encouraging this article. I am indebted to my colleagues Ken Nagata, Arthur Oakley and Tuomo Polvikoski for providing images and assistance in constructing Figs. 1, 2 and 6.

\section{Compliance with ethical standards}

Funding sources Over the past 17 years, various aspects of my work were supported by the RCUK Newcastle Centre for Brain Ageing and Vitality, Medical Research Council (UK), Alzheimer's Research UK, the Dunhill Medical Trust, UK, and the Newcastle National Institute for Health Research Biomedical Research Centre in Ageing and Age Related Diseases, Newcastle upon Tyne Hospitals National Health Service Foundation Trust.

Open Access This article is distributed under the terms of the Creative Commons Attribution 4.0 International License (http://creativecommons.org/licenses/by/4.0/), which permits unrestricted use, distribution, and reproduction in any medium, provided you give appropriate credit to the original author(s) and the source, provide a link to the Creative Commons license, and indicate if changes were made.

\section{References}

1. Akatsu H, Takahashi M, Matsukawa N, Ishikawa Y, Kondo N, Sato T, Nakazawa H, Yamada T, Okada H, Yamamoto T, Kosaka K (2002) Subtype analysis of neuropathologically diagnosed patients in a Japanese geriatric hospital. J Neurol Sci 196:63-69

2. Alafuzoff I, Arzberger T, Al-Sarraj S, Bodi I, Bogdanovic N, Braak H, Bugiani O, Del-Tredici K, Ferrer I, Gelpi E, Giaccone G, Graeber MB, Ince P, Kamphorst W, King A, Korkolopoulou P, Kovacs GG, Larionov S, Meyronet D, Monoranu C, Parchi P, Patsouris E, Roggendorf W, Seilhean D, Tagliavini F, Stadelmann C, Streichenberger N, Thal DR, Wharton SB, Kretzschmar H (2008) Staging of neurofibrillary pathology in Alzheimer's disease: a study of the BrainNet Europe Consortium. Brain Pathol 18:484-496

3. Alafuzoff I, Gelpi E, Al-Sarraj S, Arzberger T, Attems J, Bodi I, Bogdanovic N, Budka H, Bugiani O, Englund E, Ferrer I, Gentleman S, Giaccone G, Graeber MB, Hortobagyi T, Hoftberger R, Ironside JW, Jellinger K, Kavantzas N, King A, Korkolopoulou P, Kovacs GG, Meyronet D, Monoranu C, Parchi P, Patsouris E, Roggendorf W, Rozemuller A, Seilhean D, Streichenberger N, Thal DR, Wharton SB, Kretzschmar H (2012) The need to unify neuropathological assessments of vascular alterations in the ageing brain: multicentre survey by the BrainNet Europe consortium. Exp Gerontol 47:825-833

4. Allan LM, Rowan EN, Firbank MJ, Thomas AJ, Parry SW, Polvikoski TM, O’Brien JT, Kalaria RN (2012) Long term incidence of dementia, predictors of mortality and pathological diagnosis in older stroke survivors. Brain 134:3716-3727

5. Altaf N, Daniels L, Morgan PS, Lowe J, Gladman J, MacSweeney ST, Moody A, Auer DP (2006) Cerebral white matter hyperintense lesions are associated with unstable carotid plaques. Eur J Vasc Endovasc Surg 31:8-13

6. Arvanitakis Z, Leurgans SE, Barnes LL, Bennett DA, Schneider JA (2011) Microinfarct pathology, dementia, and cognitive systems. Stroke 42:722-727

7. Arvanitakis Z, Leurgans SE, Wang Z, Wilson RS, Bennett DA, Schneider JA (2011) Cerebral amyloid angiopathy pathology and cognitive domains in older persons. Ann Neurol $69: 320-327$
8. Attems J, Jellinger K, Thal DR, Van Nostrand W (2011) Review: sporadic cerebral amyloid angiopathy. Neuropathol Appl Neurobiol 37:75-93

9. Bailey EL, Smith C, Sudlow CL, Wardlaw JM (2012) Pathology of lacunar ischemic stroke in humans-a systematic review. Brain Pathol 22:583-591

10. Ballard C, McKeith I, O'Brien J, Kalaria R, Jaros E, Ince P, Perry R (2000) Neuropathological substrates of dementia and depression in vascular dementia, with a particular focus on cases with small infarct volumes. Dement Geriatr Cogn Disord 11:59-65

11. Ballard CG, Burton EJ, Barber R, Stephens S, Kenny RA, Kalaria RN, O'Brien JT (2004) NINDS AIREN neuroimaging criteria do not distinguish stroke patients with and without dementia. Neurology 63:983-988

12. Barker R, Ashby EL, Wellington D, Barrow VM, Palmer JC, Kehoe PG, Esiri MM, Love S (2014) Pathophysiology of white matter perfusion in Alzheimer's disease and vascular dementia. Brain 137:1524-1532

13. Barker WW, Luis CA, Kashuba A, Luis M, Harwood DG, Loewenstein D, Waters C, Jimison P, Shepherd E, Sevush S, Graff-Radford N, Newland D, Todd M, Miller B, Gold M, Heilman K, Doty L, Goodman I, Robinson B, Pearl G, Dickson D, Duara R (2002) Relative frequencies of Alzheimer disease, Lewy body, vascular and frontotemporal dementia, and hippocampal sclerosis in the State of Florida Brain Bank. Alzheimer Dis Assoc Disord 16:203-212

14. Bastos-Leite AJ, van der Flier WM, van Straaten EC, Staekenborg SS, Scheltens P, Barkhof F (2007) The contribution of medial temporal lobe atrophy and vascular pathology to cognitive impairment in vascular dementia. Stroke 38:3182-3185

15. Beach TG, Wilson JR, Sue LI, Newell A, Poston M, Cisneros R, Pandya Y, Esh C, Connor DJ, Sabbagh M, Walker DG, Roher AE (2007) Circle of Willis atherosclerosis: association with Alzheimer's disease, neuritic plaques and neurofibrillary tangles. Acta Neuropathol 113:13-21

16. Bejot Y, Aboa-Eboule C, Durier J, Rouaud O, Jacquin A, Ponavoy E, Richard D, Moreau T, Giroud M (2011) Prevalence of early dementia after first-ever stroke: a 24-year populationbased study. Stroke 42:607-612

17. Bennett DA, Wilson RS, Gilley DW, Fox JH (1990) Clinical diagnosis of Binswanger's disease. J Neurol Neurosurg Psychiatry 53:961-965

18. Berrios GE, Freeman HL (1991) Alzheimer and the dementia. In: Berrios GE (ed) Eponymists in medicine series. Royal Society of Medicine Services, London, pp 69-76

19. Blessed G, Tomlinson BE, Roth M (1968) The association between quantitative measures of dementia and of senile change in the cerebral grey matter of elderly subjects. Br J Psychiatry 114:797-811

20. Brandenburg S, Muller A, Turkowski K, Radev YT, Rot S, Schmidt C, Bungert AD, Acker G, Schorr A, Hippe A, Miller K, Heppner FL, Homey B, Vajkoczy P (2016) Resident microglia rather than peripheral macrophages promote vascularization in brain tumors and are source of alternative pro-angiogenic factors. Acta Neuropathol 131:365-378

21. Brown WR, Moody DM, Challa VR, Thore CR, Anstrom JA (2002) Apoptosis in leukoaraiosis lesions. J Neurol Sci 203-204:169-171

22. Brown WR, Moody DM, Challa VR, Thore CR, Anstrom JA (2002) Venous collagenosis and arteriolar tortuosity in leukoaraiosis. J Neurol Sci 203-204:159-163

23. Brown WR, Thore CR (2011) Review: cerebral microvascular pathology in ageing and neurodegeneration. Neuropathol Appl Neurobiol 37:56-74

24. Brun A (1994) Pathology and pathophysiology of cerebrovascular dementia: pure subgroups of obstructive and hypoperfusive etiology. Dementia 5:145-147 
25. Burke MJ, Nelson L, Slade JY, Oakley AE, Khundakar AA, Kalaria RN (2014) Morphometry of the hippocampal microvasculature in post-stroke and age-related dementias. Neuropathol Appl Neurobiol 40:284-295

26. Burton EJ, Barber R, Mukaetova-Ladinska EB, Robson J, Perry RH, Jaros E, Kalaria RN, O’Brien JT (2009) Medial temporal lobe atrophy on MRI differentiates Alzheimer's disease from dementia with Lewy bodies and vascular cognitive impairment: a prospective study with pathological verification of diagnosis. Brain 132:195-203

27. Cadavid D, Mena H, Koeller K, Frommelt RA (2000) Cerebral beta amyloid angiopathy is a risk factor for cerebral ischemic infarction. A case control study in human brain biopsies. J Neuropathol Exp Neurol 59:768-773

28. Caplan LR (2008) Uncommon causes of stroke. Cambridge University Press, Cambridge

29. CFAS (2001) Pathological correlates of late-onset dementia in a multicentre, community-based population in England and Wales. Neuropathology Group of the Medical Research Council Cognitive Function and Ageing Study (MRC CFAS). Lancet 357:169-175

30. Chabriat H, Joutel A, Dichgans M, Tournier-Lasserve E, Bousser MG (2009) CADASIL. Lancet Neurol 8:643-653

31. Charidimou A, Gang Q, Werring DJ (2012) Sporadic cerebral amyloid angiopathy revisited: recent insights into pathophysiology and clinical spectrum. J Neurol Neurosurg Psychiatry 83:124-137

32. Chen A, Akinyemi RO, Hase Y, Firbank MJ, Ndung'u MN, Foster V, Craggs LJ, Washida K, Okamoto Y, Thomas AJ, Polvikoski TM, Allan LM, Oakley AE, O'Brien JT, Horsburgh K, Ihara M, Kalaria RN (2016) Frontal white matter hyperintensities, clasmatodendrosis and gliovascular abnormalities in ageing and poststroke dementia. Brain 139:242-258

33. Chui HC, Victoroff JI, Margolin D, Jagust W, Shankle R, Katzman R (1992) Criteria for the diagnosis of ischemic vascular dementia proposed by the State of California Alzheimer's Disease Diagnostic and Treatment Centers. Neurology 42:473-480

34. Cohen DL, Hedera P, Premkumar DR, Friedland RP, Kalaria RN (1997) Amyloid-beta protein angiopathies masquerading as Alzheimer's disease? Ann N Y Acad Sci 826:390-395

35. Cosentino SA, Jefferson AL, Carey M, Price CC, Davis-Garrett K, Swenson R, Libon DJ (2004) The clinical diagnosis of vascular dementia: a comparison among four classification systems and a proposal for a new paradigm. Clin Neuropsychol 18:6-21

36. Craggs LJ, Hagel C, Kuhlenbaeumer G, Borjesson-Hanson A, Andersen O, Viitanen M, Kalimo H, McLean CA, Slade JY, Hall RA, Oakley AE, Yamamoto Y, Deramecourt V, Kalaria RN (2013) Quantitative vascular pathology and phenotyping familial and sporadic cerebral small vessel diseases. Brain Pathol 23:547-557

37. Craggs LJ, Yamamoto Y, Ihara M, Fenwick R, Burke M, Oakley AE, Roeber S, Duering M, Kretzschmar H, Kalaria RN (2014) White matter pathology and disconnection in the frontal lobe in CADASIL. Neuropathol Appl Neurobiol 40:591-602

38. del Ser T, Bermejo F, Portera A, Arredondo JM, Bouras C, Constantinidis J (1990) Vascular dementia. A clinicopathological study. J Neurol Sci 96:1-17

39. Deramecourt V, Slade JY, Oakley AE, Perry RH, Ince PG, Maurage CA, Kalaria RN (2012) Staging and natural history of cerebrovascular pathology in dementia. Neurology 78:1043-1050

40. Desmond DW (2004) The neuropsychology of vascular cognitive impairment: is there a specific cognitive deficit? J Neurol Sci 226:3-7

41. Desmond DW, Moroney JT, Paik MC, Sano M, Mohr JP, Aboumatar S, Tseng CL, Chan S, Williams JB, Remien RH, Hauser
WA, Stern Y (2000) Frequency and clinical determinants of dementia after ischemic stroke. Neurology 54:1124-1131

42. Elliott MS, Ballard CG, Kalaria RN, Perry R, Hortobagyi T, Francis PT (2009) Increased binding to 5-HT1A and 5-HT2A receptors is associated with large vessel infarction and relative preservation of cognition. Brain 132:1858-1865

43. Ellis RJ, Olichney JM, Thal LJ, Mirra SS, Morris JC, Beekly D, Heyman A (1996) Cerebral amyloid angiopathy in the brains of patients with Alzheimer's disease: the CERAD experience, Part XV. Neurology 46:1592-1596

44. Englund E (1998) Neuropathology of white matter changes in Alzheimer's disease and vascular dementia. Dement Geriatr Cogn Disord 9(Suppl 1):6-12

45. Erkinjuntti T, Haltia M, Palo J, Sulkava R, Paetau A (1988) Accuracy of the clinical diagnosis of vascular dementia: a prospective clinical and post-mortem neuropathological study. J Neurol Neurosurg Psychiatry 51:1037-1044

46. Erkinjuntti T, Inzitari D, Pantoni L, Wallin A, Scheltens P, Rockwood K, Desmond DW (2000) Limitations of clinical criteria for the diagnosis of vascular dementia in clinical trials. Is a focus on subcortical vascular dementia a solution? Ann N Y Acad Sci 903:262-272

47. Esiri MM, Nagy Z, Smith MZ, Barnetson L, Smith AD (1999) Cerebrovascular disease and threshold for dementia in the early stages of Alzheimer's disease. Lancet 354:919-920

48. Esiri MM, Wilcock GK, Morris JH (1997) Neuropathological assessment of the lesions of significance in vascular dementia. $\mathrm{J}$ Neurol Neurosurg Psychiatry 63:749-753

49. Fazekas F, Kleinert R, Roob G, Kleinert G, Kapeller P, Schmidt R, Hartung HP (1999) Histopathologic analysis of foci of signal loss on gradient-echo T2*-weighted MR images in patients with spontaneous intracerebral hemorrhage: evidence of microangiopathy-related microbleeds. AJNR Am J Neuroradiol 20:637-642

50. Fernando MS, Ince PG, MRC Cognitive Function Ageing Neuropathology Study G (2004) Vascular pathologies and cognition in a population-based cohort of elderly people. J Neurol Sci 226:13-17

51. Fernando MS, Simpson JE, Matthews F, Brayne C, Lewis CE, Barber R, Kalaria RN, Forster G, Esteves F, Wharton SB, Shaw PJ, O'Brien JT, Ince PG (2006) White matter lesions in an unselected cohort of the elderly: molecular pathology suggests origin from chronic hypoperfusion injury. Stroke 37:1391-1398

52. Ferro JM, Massaro AR, Mas JL (2010) Aetiological diagnosis of ischaemic stroke in young adults. Lancet Neurol 9:1085-1096

53. Filosto M, Tomelleri G, Tonin P, Scarpelli M, Vattemi G, Rizzuto N, Padovani A, Simonati A (2007) Neuropathology of mitochondrial diseases. Biosci Rep 27:23-30

54. Firbank MJ, He J, Blamire AM, Singh B, Danson P, Kalaria RN, O'Brien JT (2011) Cerebral blood flow by arterial spin labeling in poststroke dementia. Neurology 76:1478-1484

55. Fischer P, Jellinger K, Gatterer G, Danielczyk W (1991) Prospective neuropathological validation of Hachinski's Ischaemic Score in dementias. J Neurol Neurosurg Psychiatry 54:580-583

56. Fisher CM (1982) Lacunar strokes and infarcts: a review. Neurology 32:871-876

57. Foster V, Oakley AE, Slade JY, Hall R, Polvikoski TM, Burke M, Thomas AJ, Khundakar A, Allan LM, Kalaria RN (2014) Pyramidal neurons of the prefrontal cortex in post-stroke, vascular and other ageing-related dementias. Brain 137:2509-2521

58. Freitas S, Simoes MR, Alves L, Vicente M, Santana I (2012) Montreal cognitive assessment (MoCA): validation study for vascular dementia. J Int Neuropsychol Soc 18:1031-1040

59. Gemmell E, Bosomworth H, Allan L, Hall R, Khundakar A, Oakley AE, Deramecourt V, Polvikoski TM, O'Brien JT, Kalaria RN (2012) Hippocampal neuronal atrophy and 
cognitive function in delayed poststroke and aging-related dementias. Stroke 43:808-814

60. Giannakopoulos P, Gold G, Kovari E, von Gunten A, Imhof A, Bouras C, Hof PR (2007) Assessing the cognitive impact of Alzheimer disease pathology and vascular burden in the aging brain: the Geneva experience. Acta Neuropathol 113:1-12

61. Giwa MO, Williams J, Elderfield K, Jiwa NS, Bridges LR, Kalaria RN, Markus HS, Esiri MM, Hainsworth AH (2012) Neuropathologic evidence of endothelial changes in cerebral small vessel disease. Neurology 78:167-174

62. Gold G, Bouras C, Canuto A, Bergallo MF, Herrmann FR, Hof PR, Mayor PA, Michel JP, Giannakopoulos P (2002) Clinicopathological validation study of four sets of clinical criteria for vascular dementia. Am J Psychiatry 159:82-87

63. Gold G, Giannakopoulos P, Herrmann FR, Bouras C, Kovari E (2007) Identification of Alzheimer and vascular lesion thresholds for mixed dementia. Brain 130:2830-2836

64. Gorelick PB, Chatterjee A, Patel D, Flowerdew G, Dollear W, Taber J, Harris Y (1992) Cranial computed tomographic observations in multi-infarct dementia. A controlled study. Stroke 23:804-811

65. Gorelick PB, Scuteri A, Black SE, Decarli C, Greenberg SM, Iadecola C, Launer LJ, Laurent S, Lopez OL, Nyenhuis D, Petersen RC, Schneider JA, Tzourio C, Arnett DK, Bennett DA, Chui HC, Higashida RT, Lindquist R, Nilsson PM, Roman GC, Sellke FW, Seshadri S (2011) Vascular contributions to cognitive impairment and dementia: a statement for healthcare professionals from the american heart association/american stroke association. Stroke 42:2672-2713

66. Gottfries CG, Blennow K, Karlsson I, Wallin A (1994) The neurochemistry of vascular dementia. Dementia 5:163-167

67. Gould DB, Phalan FC, van Mil SE, Sundberg JP, Vahedi K, Massin P, Bousser MG, Heutink P, Miner JH, Tournier-Lasserve E, John SW (2006) Role of COL4A1 in small-vessel disease and hemorrhagic stroke. N Engl J Med 354:1489-1496

68. Gray F, Polivka M, Viswanathan A, Baudrimont M, Bousser MG, Chabriat H (2007) Apoptosis in cerebral autosomal-dominant arteriopathy with subcortical infarcts and leukoencephalopathy. J Neuropathol Exp Neurol 66:597-607

69. Greenberg SM, Nandigam RN, Delgado P, Betensky RA, Rosand J, Viswanathan A, Frosch MP, Smith EE (2009) Microbleeds versus macrobleeds: evidence for distinct entities. Stroke 40:2382-2386

70. Grinberg LT, Thal DR (2010) Vascular pathology in the aged human brain. Acta Neuropathol 119:277-290

71. Haan J, Lanser JB, Zijderveld I, van der Does IG, Roos RA (1990) Dementia in hereditary cerebral hemorrhage with amyloidosis-Dutch type. Arch Neurol 47:965-967

72. Hachinski V, Iadecola C, Petersen RC, Breteler MM, Nyenhuis DL, Black SE, Powers WJ, DeCarli C, Merino JG, Kalaria RN, Vinters HV, Holtzman DM, Rosenberg GA, Dichgans M, Marler JR, Leblanc GG (2006) National Institute of Neurological Disorders and Stroke-Canadian Stroke Network vascular cognitive impairment harmonization standards. Stroke 37:2220-2241

73. Hachinski VC, Lassen NA, Marshall J (1974) Multi-infarct dementia. A cause of mental deterioration in the elderly. Lancet 2:207-210

74. Haglund M, Passant U, Sjobeck M, Ghebremedhin E, Englund E (2006) Cerebral amyloid angiopathy and cortical microinfarcts as putative substrates of vascular dementia. Int J Geriatr Psychiatry 21:681-687

75. Hamel E (2006) Perivascular nerves and the regulation of cerebrovascular tone. J Appl Physiol 100:1059-1064

76. Hara K, Shiga A, Fukutake T, Nozaki H, Miyashita A, Yokoseki A, Kawata H, Koyama A, Arima K, Takahashi T, Ikeda M, Shiota H, Tamura M, Shimoe Y, Hirayama M, Arisato T, Yanagawa
S, Tanaka A, Nakano I, Ikeda S, Yoshida Y, Yamamoto T, Ikeuchi T, Kuwano R, Nishizawa M, Tsuji S, Onodera O (2009) Association of HTRA1 mutations and familial ischemic cerebral small-vessel disease. N Engl J Med 360:1729-1739

77. Hassan A, Hunt BJ, O'Sullivan M, Parmar K, Bamford JM, Briley D, Brown MM, Thomas DJ, Markus HS (2003) Markers of endothelial dysfunction in lacunar infarction and ischaemic leukoaraiosis. Brain 126:424-432

78. Ho KL, Garcia JH (2000) Neuropathology of the small blood vessels in selected disease of the cerebral white matter. In: Pantoni L, Inzitari D, Wallin A (eds) The matter of white matter. Academic Pharmaceutical Productions, Utrecht, pp 247-273

79. Holmes C, Cairns N, Lantos P, Mann A (1999) Validity of current clinical criteria for Alzheimer's disease, vascular dementia and dementia with Lewy bodies. Br J Psychiatry 174:45-50

80. Hulette C, Nochlin D, McKeel D, Morris JC, Mirra SS, Sumi SM, Heyman A (1997) Clinical-neuropathologic findings in multi-infarct dementia: a report of six autopsied cases. Neurology 48:668-672

81. Hyman BT, Phelps CH, Beach TG, Bigio EH, Cairns NJ, Carrillo MC, Dickson DW, Duyckaerts C, Frosch MP, Masliah E, Mirra SS, Nelson PT, Schneider JA, Thal DR, Thies B, Trojanowski JQ, Vinters HV, Montine TJ (2012) National Institute on Aging-Alzheimer's Association guidelines for the neuropathologic assessment of Alzheimer's disease. Alzheimers Dement 8:1-13

82. Ihara M, Polvikoski TM, Hall R, Slade JY, Perry RH, Oakley AE, Englund E, O'Brien JT, Ince PG, Kalaria RN (2010) Quantification of myelin loss in frontal lobe white matter in vascular dementia, Alzheimer's disease, and dementia with Lewy bodies. Acta Neuropathol 119:579-589

83. Janaway BM, Simpson JE, Hoggard N, Highley JR, Forster G, Drew D, Gebril OH, Matthews FE, Brayne C, Wharton SB, Ince PG, Function MRCC, Ageing Neuropathology S (2014) Brain haemosiderin in older people: pathological evidence for an ischaemic origin of magnetic resonance imaging (MRI) microbleeds. Neuropathol Appl Neurobiol 40:258-269

84. Jellinger KA (2008) The pathology of "vascular dementia": a critical update. J Alzheimers Dis 14:107-123

85. Jen J, Cohen AH, Yue Q, Stout JT, Vinters HV, Nelson S, Baloh RW (1997) Hereditary endotheliopathy with retinopathy, nephropathy, and stroke (HERNS). Neurology 49:1322-1330

86. Kalaria RN (2012) Cerebrovascular disease and mechanisms of cognitive impairment: evidence from clinicopathological studies in humans. Stroke 43:2526-2534

87. Kalaria RN, Ballard C (1999) Overlap between pathology of Alzheimer disease and vascular dementia. Alzheimer Dis Assoc Disord 13(Suppl 3):S115-S123

88. Kalaria RN, Ferrer I, Love S (2015) Vascular disease, hypoxia and related conditions. In: Love S, Perry A, Ironside J, Budka $\mathrm{H}$ (eds) Greenfield's neuropathology, 9th edn. CRC, London, pp 59-209

89. Kalaria RN, Hedera P (1995) Differential degeneration of the cerebral microvasculature in Alzheimer's disease. NeuroReport 6:477-480

90. Kalaria RN, Kenny RA, Ballard CG, Perry R, Ince P, Polvikoski $T$ (2004) Towards defining the neuropathological substrates of vascular dementia. J Neurol Sci 226:75-80

91. Kalaria RN, Perry RH, O’Brien J, Jaros E (2012) Atheromatous disease in small intracerebral vessels, microinfarcts and dementia. Neuropathol Appl Neurobiol 38:505-508

92. Keverne JS, Low WC, Ziabreva I, Court JA, Oakley AE, Kalaria RN (2007) Cholinergic neuronal deficits in CADASIL. Stroke 38:188-191

93. Kirvell SL, Elliott MS, Kalaria RN, Hortobagyi T, Ballard CG, Francis PT (2011) Vesicular glutamate transporter and 
cognition in stroke: a case-control autopsy study. Neurology 75:1803-1809

94. Kiuru S, Salonen O, Haltia M (1999) Gelsolin-related spinal and cerebral amyloid angiopathy. Ann Neurol 45:305-311

95. Knopman DS, Parisi JE, Boeve BF, Cha RH, Apaydin H, Salviati A, Edland SD, Rocca WA (2003) Vascular dementia in a population-based autopsy study. Arch Neurol 60:569-575

96. Kovari E, Gold G, Herrmann FR, Canuto A, Hof PR, Bouras C, Giannakopoulos P (2007) Cortical microinfarcts and demyelination affect cognition in cases at high risk for dementia. Neurology 68:927-931

97. Kovari E, Gold G, Herrmann FR, Canuto A, Hof PR, Michel JP, Bouras C, Giannakopoulos P (2004) Cortical microinfarcts and demyelination significantly affect cognition in brain aging. Stroke 35:410-414

98. Kril JJ, Patel S, Harding AJ, Halliday GM (2002) Patients with vascular dementia due to microvascular pathology have significant hippocampal neuronal loss. J Neurol Neurosurg Psychiatry 72:747-751

99. Lammie GA, Brannan F, Slattery J, Warlow C (1997) Nonhypertensive cerebral small-vessel disease. An autopsy study. Stroke 28:2222-2229

100. Launer LJ, Hughes TM, White LR (2011) Microinfarcts, brain atrophy, and cognitive function: the Honolulu Asia Aging Study Autopsy Study. Ann Neurol 70:774-780

101. Levy E, Lopez-Otin C, Ghiso J, Geltner D, Frangione B (1989) Stroke in Icelandic patients with hereditary amyloid angiopathy is related to a mutation in the cystatin $\mathrm{C}$ gene, an inhibitor of cysteine proteases. J Exp Med 169:1771-1778

102. Leys D, Henon H, Mackowiak-Cordoliani MA, Pasquier F (2005) Poststroke dementia. Lancet Neurol 4:752-759

103. Li L, Yiin GS, Geraghty OC, Schulz UG, Kuker W, Mehta Z, Rothwell PM, Oxford Vascular S (2015) Incidence, outcome, risk factors, and long-term prognosis of cryptogenic transient ischaemic attack and ischaemic stroke: a population-based study. Lancet Neurol 14:903-913

104. Liu CK, Miller BL, Cummings JL, Mehringer CM, Goldberg MA, Howng SL, Benson DF (1992) A quantitative MRI study of vascular dementia. Neurology 42:138-143

105. Longstreth WT Jr, Sonnen JA, Koepsell TD, Kukull WA, Larson EB, Montine TJ (2009) Associations between microinfarcts and other macroscopic vascular findings on neuropathologic examination in 2 databases. Alzheimer Dis Assoc Disord 23:291-294

106. Love S, Chalmers K, Ince P, Esiri M, Attems J, Kalaria R, Jellinger K, Yamada M, McCarron M, Minett T, Matthews F, Greenberg S, Mann D, Kehoe PG (2015) Erratum: development, appraisal, validation and implementation of a consensus protocol for the assessment of cerebral amyloid angiopathy in post-mortem brain tissue. Am J Neurodegener Dis 4:49

107. Mann DM, Yates PO, Marcyniuk B (1986) The nucleus basalis of Meynert in multi-infarct (vascular) dementia. Acta Neuropathol 71:332-337

108. Matthews FE, Brayne C, Lowe J, McKeith I, Wharton SB, Ince $P$ (2009) Epidemiological pathology of dementia: attributablerisks at death in the Medical Research Council Cognitive Function and Ageing Study. PLoS Med 6:e1000180

109. Mead S, James-Galton M, Revesz T, Doshi RB, Harwood G, Pan EL, Ghiso J, Frangione B, Plant G (2000) Familial British dementia with amyloid angiopathy: early clinical, neuropsychological and imaging findings. Brain 123(Pt 5):975-991

110. Mirra SS (1997) The CERAD neuropathology protocol and consensus recommendations for the postmortem diagnosis of Alzheimer's disease: a commentary. Neurobiol Aging 18:S91-S94

111. Montine TJ, Phelps $\mathrm{CH}$, Beach TG, Bigio EH, Cairns NJ, Dickson DW, Duyckaerts C, Frosch MP, Masliah E, Mirra SS,
Nelson PT, Schneider JA, Thal DR, Trojanowski JQ, Vinters HV, Hyman BT, National Institute on A, Alzheimer's A (2012) National Institute on Aging-Alzheimer's Association guidelines for the neuropathologic assessment of Alzheimer's disease: a practical approach. Acta Neuropathol 123:1-11

112. Mulugeta E, Molina-Holgado F, Elliott MS, Hortobagyi T, Perry R, Kalaria RN, Ballard CG, Francis PT (2008) Inflammatory mediators in the frontal lobe of patients with mixed and vascular dementia. Dement Geriatr Cogn Disord 25:278-286

113. Nagy Z, Esiri MM, Jobst KA, Morris JH, King EM, McDonald B, Joachim C, Litchfield S, Barnetson L, Smith AD (1997) The effects of additional pathology on the cognitive deficit in Alzheimer disease. J Neuropathol Exp Neurol 56:165-170

114. Natte R, Maat-Schieman ML, Haan J, Bornebroek M, Roos RA, van Duinen SG (2001) Dementia in hereditary cerebral hemorrhage with amyloidosis-Dutch type is associated with cerebral amyloid angiopathy but is independent of plaques and neurofibrillary tangles. Ann Neurol 50:765-772

115. Nelson PT, Schmitt FA, Lin Y, Abner EL, Jicha GA, Patel E, Thomason PC, Neltner JH, Smith CD, Santacruz KS, Sonnen JA, Poon LW, Gearing M, Green RC, Woodard JL, Van Eldik LJ, Kryscio RJ (2011) Hippocampal sclerosis in advanced age: clinical and pathological features. Brain 134:1506-1518

116. Neltner JH, Abner EL, Baker S, Schmitt FA, Kryscio RJ, Jicha GA, Smith CD, Hammack E, Kukull WA, Brenowitz WD, Van Eldik LJ, Nelson PT (2014) Arteriolosclerosis that affects multiple brain regions is linked to hippocampal sclerosis of ageing. Brain 137:255-267

117. Nolan KA, Lino MM, Seligmann AW, Blass JP (1998) Absence of vascular dementia in an autopsy series from a dementia clinic. J Am Geriatr Soc 46:597-604

118. O'Brien JT, Erkinjuntti T, Reisberg B, Roman G, Sawada T, Pantoni L, Bowler JV, Ballard C, DeCarli C, Gorelick PB, Rockwood K, Burns A, Gauthier S, DeKosky ST (2003) Vascular cognitive impairment. Lancet Neurol 2:89-98

119. O'Sullivan M, Ngo E, Viswanathan A, Jouvent E, Gschwendtner A, Saemann PG, Duering M, Pachai C, Bousser M-G, Chabriat H, Dichgans M (2009) Hippocampal volume is an independent predictor of cognitive performance in CADASIL. Neurobiol Aging 30:890-897

120. Okamoto Y, Ihara M, Fujita Y, Ito H, Takahashi R, Tomimoto H (2009) Cortical microinfarcts in Alzheimer's disease and subcortical vascular dementia. NeuroReport 20:990-996

121. Okamoto Y, Yamamoto T, Kalaria RN, Senzaki H, Maki T, Hase Y, Kitamura A, Washida K, Yamada M, Ito H, Tomimoto H, Takahashi R, Ihara M (2012) Cerebral hypoperfusion accelerates cerebral amyloid angiopathy and promotes cortical microinfarcts. Acta Neuropathol 123:381-394

122. Olichney JM, Hansen LA, Hofstetter CR, Grundman M, Katzman R, Thal LJ (1995) Cerebral infarction in Alzheimer's disease is associated with severe amyloid angiopathy and hypertension. Arch Neurol 52:702-708

123. Olichney JM, Hansen LA, Lee JH, Hofstetter CR, Katzman R, Thal LJ (2000) Relationship between severe amyloid angiopathy, apolipoprotein E genotype, and vascular lesions in Alzheimer's disease. Ann N Y Acad Sci 903:138-143

124. Ophoff RA, DeYoung J, Service SK, Joosse M, Caffo NA, Sandkuijl LA, Terwindt GM, Haan J, van den Maagdenberg AM, Jen J, Baloh RW, Barilla-LaBarca ML, Saccone NL, Atkinson JP, Ferrari MD, Freimer NB, Frants RR (2001) Hereditary vascular retinopathy, cerebroretinal vasculopathy, and hereditary endotheliopathy with retinopathy, nephropathy, and stroke map to a single locus on chromosome 3p21.1-p21.3. Am J Hum Genet 69:447-453 
125. Pantoni L (2010) Cerebral small vessel disease: from pathogenesis and clinical characteristics to therapeutic challenges. Lancet Neurol 9:689-701

126. Pantoni L, Garcia JH (1997) Pathogenesis of leukoaraiosis: a review. Stroke 28:652-659

127. Pantoni L, Sarti C, Alafuzoff I, Jellinger K, Munoz DG, Ogata J, Palumbo V (2006) Postmortem examination of vascular lesions in cognitive impairment: a survey among neuropathological services. Stroke 37:1005-1009

128. Pavlovic AM, Zidverc-Trajkovic J, Milovic MM, Pavlovic DM, Jovanovic Z, Mijajlovic M, Petrovic M, Kostic VS, Sternic N (2005) Cerebral small vessel disease in pseudoxanthoma elasticum: three cases. Can J Neurol Sci 32:115-118

129. Pendlebury ST, Rothwell PM (2009) Prevalence, incidence, and factors associated with pre-stroke and post-stroke dementia: a systematic review and meta-analysis. Lancet Neurol 8:1006-1018

130. Perry EK, Gibson PH, Blessed G, Perry RH, Tomlinson BE (1977) Neurotransmitter enzyme abnormalities in senile dementia. Choline acetyltransferase and glutamic acid decarboxylase activities in necropsy brain tissue. J Neurol Sci 34:247-265

131. Pfeifer LA, White LR, Ross GW, Petrovitch H, Launer LJ (2002) Cerebral amyloid angiopathy and cognitive function: the HAAS autopsy study. Neurology 58:1629-1634

132. Plant GT, Revesz T, Barnard RO, Harding AE, Gautier-Smith PC (1990) Familial cerebral amyloid angiopathy with nonneuritic amyloid plaque formation. Brain 113(Pt 3):721-747

133. Pohjasvaara T, Erkinjuntti T, Vataja R, Kaste M (1997) Dementia three months after stroke. Baseline frequency and effect of different definitions of dementia in the Helsinki Stroke Aging Memory Study (SAM) cohort. Stroke 28:785-792

134. Pohjasvaara T, Erkinjuntti T, Ylikoski R, Hietanen M, Vataja R, Kaste M (1998) Clinical determinants of poststroke dementia. Stroke 29:75-81

135. Pohjasvaara T, Mantyla R, Ylikoski R, Kaste M, Erkinjuntti T (2000) Comparison of different clinical criteria (DSM-III, ADDTC, ICD-10, NINDS-AIREN, DSM-IV) for the diagnosis of vascular dementia. National Institute of Neurological Disorders and Stroke-Association Internationale pour la Recherche et l'Enseignement en Neurosciences. Stroke 31:2952-2957

136. Premkumar DR, Cohen DL, Hedera P, Friedland RP, Kalaria RN (1996) Apolipoprotein E-epsilon4 alleles in cerebral amyloid angiopathy and cerebrovascular pathology associated with Alzheimer's disease. Am J Pathol 148:2083-2095

137. Rauramaa T, Pikkarainen M, Englund E, Ince PG, Jellinger K, Paetau A, Alafuzoff I (2013) Consensus recommendations on pathologic changes in the hippocampus: a postmortem multicenter inter-rater study. J Neuropathol Exp Neurol 72:452-461

138. Reijmer YD, van Veluw SJ, Greenberg SM (2015) Ischemic brain injury in cerebral amyloid angiopathy. J Cereb Blood Flow Metab. doi:10.1038/jcbfm.2015.88

139. Revesz T, Holton JL, Lashley T, Plant G, Frangione B, Rostagno A, Ghiso J (2009) Genetics and molecular pathogenesis of sporadic and hereditary cerebral amyloid angiopathies. Acta Neuropathol 118:115-130

140. Riekse RG, Leverenz JB, McCormick W, Bowen JD, Teri L, Nochlin D, Simpson K, Eugenio C, Larson EB, Tsuang D (2004) Effect of vascular lesions on cognition in Alzheimer's disease: a community-based study. J Am Geriatr Soc 52:1442-1448

141. Roher AE, Esh C, Kokjohn T, Sue L, Beach T (2005) Atherosclerosis and AD: analysis of data from the US National Alzheimer's Coordinating Center. Neurology 65:974 (author reply 974)
142. Roman GC (2002) Vascular dementia revisited: diagnosis, pathogenesis, treatment, and prevention. Med Clin North Am 86:477-499

143. Roman GC, Kalaria RN (2006) Vascular determinants of cholinergic deficits in Alzheimer disease and vascular dementia. Neurobiol Aging 27:1769-1785

144. Roman GC, Tatemichi TK, Erkinjuntti T, Cummings JL, Masdeu JC, Garcia JH, Amaducci L, Orgogozo JM, Brun A, Hofman A et al (1993) Vascular dementia: diagnostic criteria for research studies. Report of the NINDS-AIREN International Workshop. Neurology 43:250-260

145. Sachdev P (1999) Vascular cognitive disorder. Int J Geriatr Psychiatry 14:402-403

146. Sachdev P, Kalaria R, O'Brien J, Skoog I, Alladi S, Black SE, Blacker D, Blazer DG, Chen C, Chui H, Ganguli M, Jellinger K, Jeste DV, Pasquier F, Paulsen J, Prins N, Rockwood K, Roman G, Scheltens P, Internationlal Society for Vascular B, Cognitive D (2014) Diagnostic criteria for vascular cognitive disorders: a VASCOG statement. Alzheimer Dis Assoc Disord 28:206-218

147. Scher AI, Xu Y, Korf ES, Hartley SW, Witter MP, Scheltens P, White LR, Thompson PM, Toga AW, Valentino DJ, Launer LJ (2011) Hippocampal morphometry in population-based incident Alzheimer's disease and vascular dementia: the HAAS. J Neurol Neurosurg Psychiatry 82:373-376

148. Schneider JA, Arvanitakis Z, Bang W, Bennett DA (2007) Mixed brain pathologies account for most dementia cases in community-dwelling older persons. Neurology 69:2197-2204

149. Schneider JA, Arvanitakis Z, Leurgans SE, Bennett DA (2009) The neuropathology of probable Alzheimer disease and mild cognitive impairment. Ann Neurol 66:200-208

150. Seno H, Ishino H, Inagaki T, Iijima M, Kaku K, Inata T (1999) A neuropathological study of dementia in nursing homes over a 17-year period, in Shimane Prefecture, Japan. Gerontology 45:44-48

151. Sharp SI, Francis PT, Elliott MS, Kalaria RN, Bajic N, Hortobagyi T, Ballard CG (2009) Choline acetyltransferase activity in vascular dementia and stroke. Dement Geriatr Cogn Disord 28:233-238

152. Simpson JE, Fernando MS, Clark L, Ince PG, Matthews F, Forster G, O’Brien JT, Barber R, Kalaria RN, Brayne C, Shaw PJ, Lewis CE, Wharton SB, Function MRCC, Ageing Neuropathology Study G (2007) White matter lesions in an unselected cohort of the elderly: astrocytic, microglial and oligodendrocyte precursor cell responses. Neuropathol Appl Neurobiol 33:410-419

153. Simpson JE, Hosny O, Wharton SB, Heath PR, Holden H, Fernando MS, Matthews F, Forster G, O'Brien JT, Barber R, Kalaria RN, Brayne C, Shaw PJ, Lewis CE, Ince PG (2009) Microarray RNA expression analysis of cerebral white matter lesions reveals changes in multiple functional pathways. Stroke 40:369-375

154. Sinclair LI, Tayler HM, Love S (2015) Synaptic protein levels altered in vascular dementia. Neuropathol Appl Neurobiol 41:533-543

155. Smallwood A, Oulhaj A, Joachim C, Christie S, Sloan C, Smith AD, Esiri M (2012) Cerebral subcortical small vessel disease and its relation to cognition in elderly subjects: a pathological study in the Oxford Project to Investigate Memory and Ageing (OPTIMA) cohort. Neuropathol Appl Neurobiol 38:337-343

156. Snowdon DA, Greiner LH, Mortimer JA, Riley KP, Greiner PA, Markesbery WR (1997) Brain infarction and the clinical expression of Alzheimer disease. The Nun Study. JAMA 277:813-817

157. Sonnen JA, Larson EB, Crane PK, Haneuse S, Li G, Schellenberg GD, Craft S, Leverenz JB, Montine TJ (2007) Pathological 
correlates of dementia in a longitudinal, population-based sample of aging. Ann Neurol 62:406-413

158. Strozyk D, Dickson DW, Lipton RB, Katz M, Derby CA, Lee S, Wang C, Verghese J (2010) Contribution of vascular pathology to the clinical expression of dementia. Neurobiol Aging 31:1710-1720

159. Suter OC, Sunthorn T, Kraftsik R, Straubel J, Darekar P, Khalili K, Miklossy J (2002) Cerebral hypoperfusion generates cortical watershed microinfarcts in Alzheimer disease. Stroke 33:1986-1992

160. Tanskanen M, Kalaria RN, Notkola IL, Makela M, Polvikoski T, Myllykangas L, Sulkava R, Kalimo H, Paetau A, Scheltens P, Barkhof F, van Straaten E, Erkinjuntti T (2013) Relationships between white matter hyperintensities, cerebral amyloid angiopathy and dementia in a population-based sample of the oldest old. Curr Alzheimer Res 10:1090-1097

161. Tatlisumak T, Putaala J, Debette S (2014) Less common causes of stroke: diagnosis and management. In: Norrving B (ed) Oxford textbook of stroke and cerebrovasular disease, 1st edn. Oxford University Press, Oxford, pp 153-162

162. Terwindt GM, Haan J, Ophoff RA, Groenen SM, Storimans CW, Lanser JB, Roos RA, Bleeker-Wagemakers EM, Frants RR, Ferrari MD (1998) Clinical and genetic analysis of a large Dutch family with autosomal dominant vascular retinopathy, migraine and Raynaud's phenomenon. Brain 121:303-316

163. Thomas T, Miners S, Love S (2015) Post-mortem assessment of hypoperfusion of cerebral cortex in Alzheimer's disease and vascular dementia. Brain 138:1059-1069

164. Toledo JB, Arnold SE, Raible K, Brettschneider J, Xie SX, Grossman M, Monsell SE, Kukull WA, Trojanowski JQ (2013) Contribution of cerebrovascular disease in autopsy confirmed neurodegenerative disease cases in the National Alzheimer's Coordinating Centre. Brain 136:2697-2706

165. Tomlinson BE, Blessed G, Roth M (1970) Observations on the brains of demented old people. J Neurol Sci 11:205-242

166. Vahedi K, Massin P, Guichard JP, Miocque S, Polivka M, Goutieres F, Dress D, Chapon F, Ruchoux MM, Riant F, Joutel A, Gaudric A, Bousser MG, Tournier-Lasserve E (2003) Hereditary infantile hemiparesis, retinal arteriolar tortuosity, and leukoencephalopathy. Neurology 60:57-63

167. van de Pol L, Gertz HJ, Scheltens P, Wolf H (2011) Hippocampal atrophy in subcortical vascular dementia. Neurodegener Dis 8:465-469

168. Van der Flier WM, Cordonnier C (2012) Microbleeds in vascular dementia: clinical aspects. Exp Gerontol 47:853-857

169. Verreault S, Joutel A, Riant F, Neves G, Rui Silva M, Maciazek J, Tournier-Lasserve E, Bousser MG, Chabriat H (2006) A novel hereditary small vessel disease of the brain. Ann Neurol 59:353-357

170. Vidal R, Frangione B, Rostagno A, Mead S, Revesz T, Plant G, Ghiso J (1999) A stop-codon mutation in the BRI gene associated with familial British dementia. Nature 399:776-781

171. Vidal R, Revesz T, Rostagno A, Kim E, Holton JL, Bek T, Bojsen-Moller M, Braendgaard H, Plant G, Ghiso J, Frangione $\mathrm{B}$ (2000) A decamer duplication in the $3^{\prime}$ region of the BRI gene originates an amyloid peptide that is associated with dementia in a Danish kindred. Proc Natl Acad Sci USA 97:4920-4925

172. Vieira RT, Caixeta L, Machado S, Silva AC, Nardi AE, AriasCarrion O, Carta MG (2013) Epidemiology of early-onset dementia: a review of the literature. Clin Pract Epidemiol Ment Health 9:88-95

173. Vinters HV, Ellis WG, Zarow C, Zaias BW, Jagust WJ, Mack WJ, Chui HC (2000) Neuropathologic substrates of ischemic vascular dementia. J Neuropathol Exp Neurol 59:931-945
174. Viswanathan A, Patel P, Rahman R, Nandigam RN, Kinnecom C, Bracoud L, Rosand J, Chabriat H, Greenberg SM, Smith EE (2008) Tissue microstructural changes are independently associated with cognitive impairment in cerebral amyloid angiopathy. Stroke 39:1988-1992

175. Wardlaw JM (2010) Blood-brain barrier and cerebral small vessel disease. J Neurol Sci 299:66-71

176. Wattendorff AR, Bots GT, Went LN, Endtz LJ (1982) Familial cerebral amyloid angiopathy presenting as recurrent cerebral haemorrhage. J Neurol Sci 55:121-135

177. Werring DJ, Gregoire SM, Cipolotti L (2011) Cerebral microbleeds and vascular cognitive impairment. J Neurol Sci 299:131-135

178. Westover MB, Bianchi MT, Yang C, Schneider JA, Greenberg SM (2013) Estimating cerebral microinfarct burden from autopsy samples. Neurology 80:1365-1369

179. White L (2009) Brain lesions at autopsy in older JapaneseAmerican men as related to cognitive impairment and dementia in the final years of life: a summary report from the HonoluluAsia aging study. J Alzheimers Dis 18:713-725

180. White L, Petrovitch H, Hardman J, Nelson J, Davis DG, Ross GW, Masaki K, Launer L, Markesbery WR (2002) Cerebrovascular pathology and dementia in autopsied Honolulu-Asia Aging Study participants. Ann N Y Acad Sci 977:9-23

181. White L, Small BJ, Petrovitch H, Ross GW, Masaki K, Abbott RD, Hardman J, Davis D, Nelson J, Markesbery W (2005) Recent clinical-pathologic research on the causes of dementia in late life: update from the Honolulu-Asia Aging Study. J Geriatr Psychiatry Neurol 18:224-227

182. Wiederkehr S, Simard M, Fortin C, van Reekum R (2008) Comparability of the clinical diagnostic criteria for vascular dementia: a critical review. Part I. J Neuropsychiatry Clin Neurosci 20:150-161

183. Wiederkehr S, Simard M, Fortin C, van Reekum R (2008) Validity of the clinical diagnostic criteria for vascular dementia: a critical review. Part II. J Neuropsychiatry Clin Neurosci 20:162-177

184. Wolburg H, Paulus W (2010) Choroid plexus: biology and pathology. Acta Neuropathol 119:75-88

185. Yamamoto Y, Craggs L, Baumann M, Kalimo H, Kalaria RN (2011) Molecular genetics and pathology of hereditary small vessel diseases of the brain. Neuropathol Appl Neurobiol 37:94-113

186. Yamamoto Y, Ihara M, Tham C, Low RW, Slade JY, Moss T, Oakley AE, Polvikoski T, Kalaria RN (2009) Neuropathological correlates of temporal pole white matter hyperintensities in CADASIL. Stroke 40:2004-2011

187. Yarchoan M, Xie SX, Kling MA, Toledo JB, Wolk DA, Lee EB, Van Deerlin V, Lee VM, Trojanowski JQ, Arnold SE (2012) Cerebrovascular atherosclerosis correlates with Alzheimer pathology in neurodegenerative dementias. Brain 135:3749-3756

188. Zarow C, Vinters HV, Ellis WG, Weiner MW, Mungas D, White L, Chui HC (2005) Correlates of hippocampal neuron number in Alzheimer's disease and ischemic vascular dementia. Ann Neurol 57:896-903

189. Zarow C, Weiner MW, Ellis WG, Chui HC (2012) Prevalence, laterality, and comorbidity of hippocampal sclerosis in an autopsy sample. Brain Behav 2:435-442

190. Zekry D, Duyckaerts C, Moulias R, Belmin J, Geoffre C, Herrmann F, Hauw JJ (2002) Degenerative and vascular lesions of the brain have synergistic effects in dementia of the elderly. Acta Neuropathol 103:481-487 